\title{
A protein-RNA interaction network facilitates the template-independent cooperative assembly on RNA polymerase of a stable antitermination complex containing the $\boldsymbol{\lambda} \mathbf{N}$ protein
}

\author{
Jeremy Mogridge, Thien-Fah Mah, and Jack Greenblatt ${ }^{1}$ \\ Banting and Best Department of Medical Research and Department of Molecular and Medical Genetics, University of \\ Toronto, Toronto, Canada M5G 1L6
}

The stable association of the $\boldsymbol{N}$ gene transcriptional antiterminator protein of bacteriophage $\lambda$ with transcribing RNA polymerase requires a nut site $($ box $A+b o x B)$ in the nascent transcript and the Escherichia coli factors NusA, NusB, NusG, and ribosomal protein S10. We have used electrophoretic mobility shift assays to analyze the assembly of $N$ protein, the $E$. coli factors, and RNA polymerase onto the nut site RNA in the absence of a DNA template. We show that $N$ binds boxB RNA and that subsequent association of NusA with the $\mathrm{N}$-nut site complex is facilitated by both box $A$ and box $B$. In the presence of $N$, NusA, and RNA polymerase the nut site assembles ribonucleoprotein complexes containing NusB, NusG, and S10. The effects on assembly of mutations in $\operatorname{box} A, \operatorname{box} B$, NusA, and RNA polymerase define multiple weak protein-protein and protein-RNA interactions (e.g., NusB with NusG; NusA with boxB; NusA, NusB, and NusG with boxA) that contribute to the overall stability of the complex. Interaction of each component of the complex with two or more other components can explain the many observed cooperative binding associations in the DNA-independent assembly of a stable antitermination complex on RNA polymerase.

[Key Words: Transcriptional antitermination; N protein; Nus factors; bacteriophage $\lambda$; nut site]

Received July 12, 1995; revised version accepted September 28, 1995.

The $\mathrm{N}$ protein of bacteriophage $\lambda$ modifies Escherichia coli RNA polymerase so that it ignores transcription termination signals located in the two early operons of the phage (for review, see Greenblatt et al. 1993) (see Fig. 1A). This modification of RNA polymerase requires a nut site situated between the promoter and the first terminator of each operon (Salstrom and Szybalski 1978; de Crombrugghe et al. 1979; Olson et al. 1982). The nut site consists of two genetically defined elements, box $A$ and box $B$ (see Fig. 2A). The boxB DNA sequence is characterized by hyphenated dyad symmetry (Rosenberg et al. 1978), resulting in a stem-loop structure in the nascent RNA (Steege et al. 1987; Nodwell and Greenblatt 1991) and is essential for transcriptional antitermination (Salstrom and Szybalski 1978; Doelling and Franklin 1990; Whalen and Das 1990; Mason et al. 1992a). boxA is a sequence $5^{\prime}$ to $\operatorname{box} B$ that is conserved among the lambdoid phages (Friedman and Olson 1983; Olson et al. 1984) and is very similar to the box $A$ antiterminator elements that are found in the E. coli RNA $(r r n)$ operons $(\mathrm{Li}$

\footnotetext{
${ }^{1}$ Corresponding author.
}

et al, 1984). Unlike $\operatorname{rrn} \operatorname{box} A$, which is sufficient to prevent termination at Rho-dependent terminators (Morgan 1986; Berg et al. 1989; Albrechtsen et al. 1990|, $\lambda$ boxA requires $\mathrm{N}$ and $\operatorname{box} B$ to participate in antitermination (Salstrom and Szybalski 1978). Alteration of $\lambda$ box $A$ (CGCUCUUACACA) to a consensus version of box $A$ (CGCUCUUUAACA) that closely resembles rrn box $A$ (UGCUCUUUAACA) suppresses the effects on antitermination of particular mutations in $E$. coli host factors that are needed for antitermination by $\mathrm{N}$ (Friedman et al. 1990). box $A$ is required for antitermination to occur far downstream of the nut site both in vivo and in vitro (Olson et al. 1982; Robledo et al. 1990; Li et al. 1992) but is not required by $N$ to antiterminate at the $t_{R 1}$ terminator just distal to nutR in vivo (Peltz et al. 1985; Zuber et al. 1987; Patterson et al. 1994).

The host factors NusA, NusB, S10, and NusG are all involved in N-mediated antitermination (Friedman and Baron 1974; Keppel et al. 1974; Friedman et al. 1976, 1981; Das et al. 1985; Downing et al. 1990; Li et al. 1992; Sullivan et al. 1992). Transcription of the nut site allows for the stable association with the elongation complex of $\mathrm{N}$, the nut site RNA, and all four host factors (Barik et al. 
A

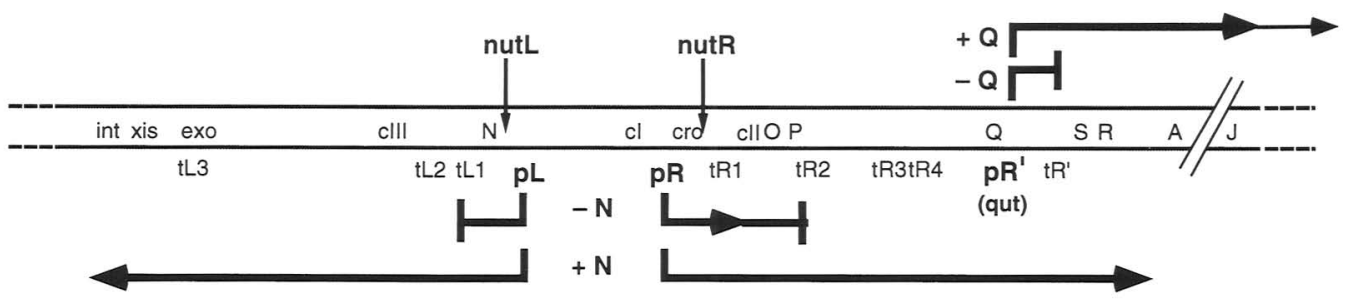

B

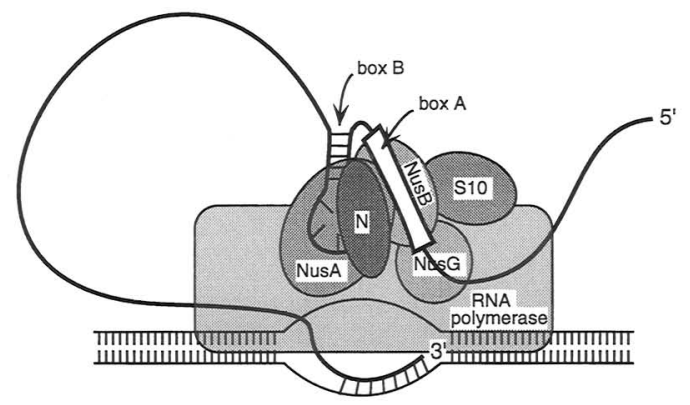

Figure 1. (A) Partial genetic and transcriptional map of bacteriophage $\lambda$ showing the positions of the nut and qut sites recognized by the $\mathrm{N}$ and Q proteins, respectively, and the antitermination effects of $\mathrm{N}$ and $\mathrm{Q}$ (adapted from Fig. 1A of Greenblatt et al. 1993). (B) Antitermination by $\mathrm{N}$ involves RNA looping and the assembly on the surface of RNA polymerase of a ribonucleoprotein complex containing N, the Nus factors, and the nut site RNA (box $A+$ boxB) (Greenblatt 1984; Nodwell and Greenblatt 1991, 1993).

1987; Horwitz et al. 1987; Mason and Greenblatt 1991; Nodwell and Greenblatt 1991). Many protein-protein interactions within this complex have been identified (see Fig. 1B): N with NusA (Greenblatt and Li 1981a); NusA, NusG, and S10 with RNA polymerase (Greenblatt and Li 1981b; Mason and Greenblatt 1991; Li et al. 1992); and NusB with S10 (Mason et al. 1992b). As well, the boxB element of the nut site RNA is bound by N (Das 1992; Nodwell 1993; Chattopadhyay et al. 1995; Tan and Frankel 1995), and the consensus and rrn versions of $\operatorname{box} A$, but not $\lambda$ box $A$, are directly recognized by a heterodimer containing NusB and S10 (Nodwell and Greenblatt 1991). All of these interactions are thought to be important for the stable association of an N-containing ribonucleoprotein complex with RNA polymerase (Nodwell and Greenblatt 1991; Mason et al. 1992a).

A minimal $\mathrm{N}$-modified transcription complex containing only $\mathrm{N}$ and NusA is able to ignore pause signals and transcribe in vitro through both Rho-dependent and -independent terminators located only a short distance downstream from a nut site (Whalen et al. 1988; Whalen and Das 1990; Mason et al. 1992a). However, highly processive antitermination through multiple terminators far downstream from a nut site additionally requires NusB, S10, and NusG, suggesting that processive antitermination is dependent on a very stable elongation complex containing all of the Nus factors (Mason et al. 1992a).

A characteristic feature of this control system is the formation of an RNA loop connecting the catalytic center of RNA polymerase to a complex on the surface of RNA polymerase that contains $\mathrm{N}$ and the Nus factors /Greenblatt 1984; Whalen and Das 1990; Nodwell and
Greenblatt 1991) (see Fig. 1B). In effect, the nut site behaves as an RNA enhancer that moves along with RNA polymerase as part of a ribonucleoprotein complex. As RNA polymerase moves downstream from a nut site and the RNA loop grows, its tethering effect is lost and the resulting unstable complex containing only $\mathrm{N}$ and Nus $\mathrm{A}$ tends to dissociate from RNA polymerase (Nodwell and Greenblatt 1991). Dissociation is prevented when NusB, S10, and NusG increase the stability of the complex (Mason and Greenblatt 1991).

We have now used gel mobility shift assays to examine the assembly of N, RNA polymerase, and the Nus factors onto radiolabeled nut site RNA in the absence of template DNA. Our results show that nucleotides in the loop of box $B$ are critical for the binding of $\mathrm{N}$ to $b o x B$, that stable association of NusA with the $\mathrm{N}-$ nut site complex requires both box $A$ and critical nucleotides in the loop of boxB, and that interaction of NusB, NusG, and $\mathrm{S} 10$ with the nut site requires the preassembly of $\mathrm{N}$, NusA, and RNA polymerase. Mutations in $b o x B$, box $A$, NusA, and RNA polymerase each affect a particular step in the assembly of the complex. Our results provide evidence for the existence of novel protein-protein and protein-RNA interactions that are important for the assembly of the $\mathrm{N}$-modified transcription complex and indicate that a large network of weak interactions is responsible for the stability of the complex.

\section{Results}

Requirements for binding of $N$ and NusA to the nut site

Genetic experiments with the $N$ genes of various lamb- 


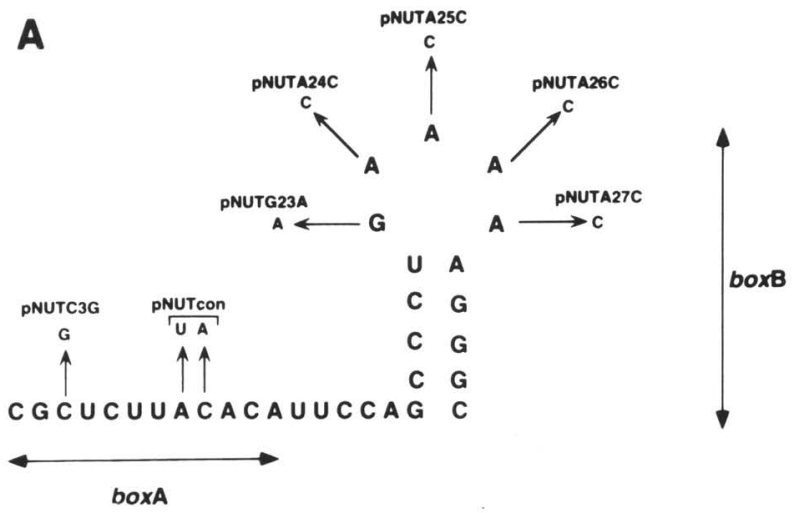

B

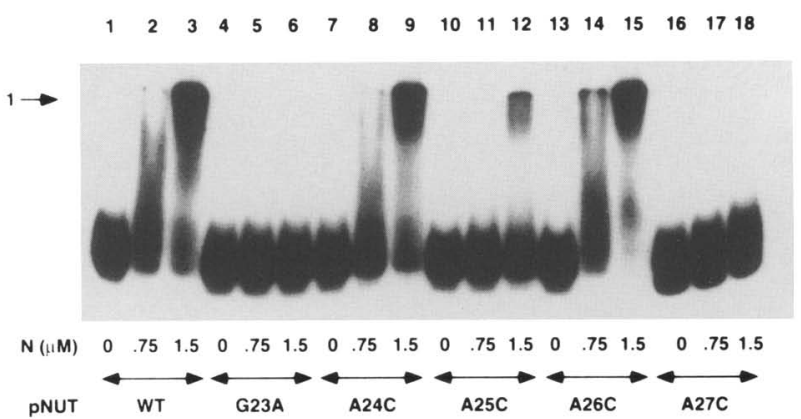

C $\begin{array}{lllllllllllllll}1 & 2 & 3 & 4 & 5 & 6 & 7 & 8 & 9 & 10 & 11 & 12 & 13 & 14 & 15\end{array}$

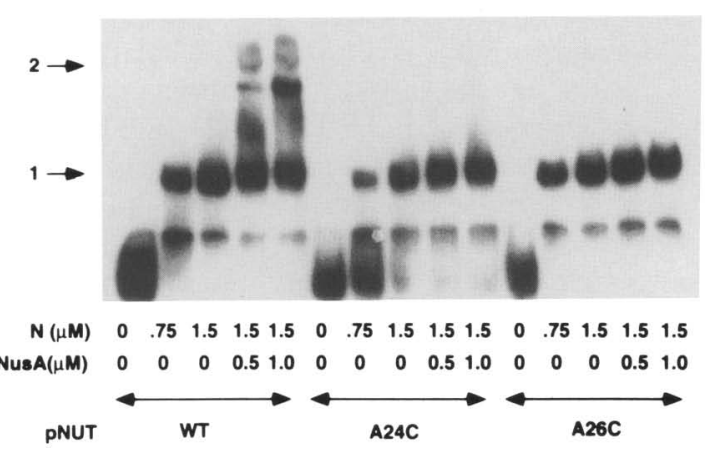

D

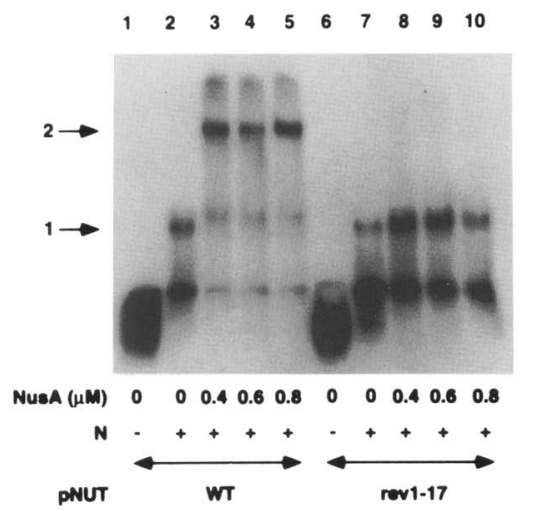

E $\begin{array}{llllllll}1 & 2 & 3 & 4 & 5 & 6 & 7 & 8\end{array}$

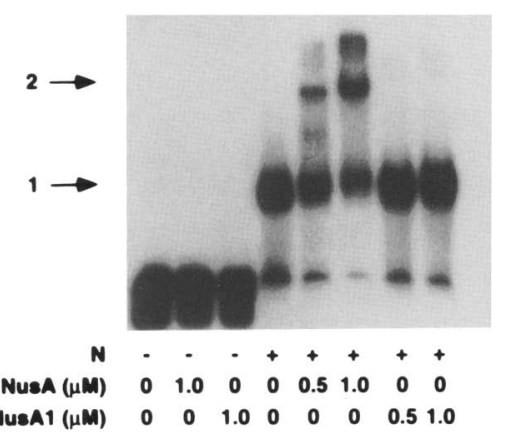

Figure 2. Mutations in the nut site affect the binding of $\mathbf{N}$ and NusA. Reactions containing ${ }^{32} \mathrm{P}$-labeled wild-type or the indicated mutant nut site RNA were electrophoresed on nondenaturing gels, dried, and exposed to film. The positions of various protein-RNA complexes are indicated. See text for the designations used for various complexes. $(A)$ The $\lambda$ nut $R$ site and the various mutations used in our experiments. (B) Mutations in the loop of $b o x B$ affect the binding of $\mathrm{N}$. Various concentrations of $\mathrm{N}$ were incubated with wild-type or mutant nut site RNA, as indicated. $(C)$ Mutations in the loop of box $B$ affect the assembly of NusA onto an $\mathrm{N}-$ nut site complex. The indicated concentrations of $\mathrm{N}$ and NusA were incubated with wild-type or mutant nut site RNA. The reactions were electrophoresed on a $7.5 \%$ nondenaturing polyacrylamide gel. $(D)$ box $A$ is important for the formation of an N-NusA-nut site complex. $\mathrm{N}(1.5 \mu \mathrm{M})$ was incubated in the presence or absence of NusA (as indicated) with pNUTWT or pNUTrev1-17 RNA (containing the sequence ACCUUACACAUUCUCGCGCCCUGAAAAAGGGC). The reactions were electrophoresed on a $7.5 \%$ nondenaturing polyacrylamide gel. (E) The nusA1 mutation affects the assembly of the N-NusA-nut site complex. $\mathrm{N}(1.5 \mu \mathrm{M})$ was incubated with wild-type nut site RNA in the presence or absence of NusA or NusAl, as indicated. The reactions were electrophoresed on a $7.5 \%$ nondenaturing polyacrylamide gel.

doid bacteriophages have indicated that their $\mathrm{N}$ proteins ought to recognize the box $B$ elements of their respective nut sites (Lazinski et al. 1989). To directly examine the interaction of $\mathrm{N}$ with the nut site, we incubated purified $\lambda \mathrm{N}$ protein with ${ }^{32} \mathrm{P}$-labeled RNA containing a wildtype nut site and subjected the reactions to electrophoresis on a nondenaturing polyacrylamide gel (Fig. 2B, lanes 1-3). At $1.5 \mu \mathrm{M} \mathrm{N}$ (lane 3), most of the RNA was shifted to form complex 1 (see Table 1 for a list of the various complexes formed in our mobility shift experi- ments). Because mutations in all the nucleotides of the loop of boxB impair antitermination in vivo (see Fig. 2A; Doelling and Franklin 1989), we tested the effects of $\mathrm{mu}$ tations in the box $B$ loop on $\mathrm{N}$ binding (lanes 4-18). Changing the first and fifth nucleotides in the loop of box $B$ virtually abolished the binding of $\mathrm{N}$ (lanes 4-6, 16-18), and mutating the third nucleotide had a significant, but more modest, effect on the binding of $\mathrm{N}$ (lanes 10-12). Chattopadhyay et al. (1995) have made similar observations but did not detect an effect of mutating the 
Table 1. Complexes formed by the addition of various proteins to nut site RNA and observed in gel mobility shift experiments

\begin{tabular}{ll}
\hline Complex & Components $^{\mathrm{a}}$ \\
\hline 1 & N-nut \\
2 & N-NusA-nut \\
3 & RNAP-nut \\
4 & RNAP-NusA-nut \\
5 & RNAP-NusA-N-nut \\
$6^{\text {b }}$ & RNAP-NusA-N-NusG-nut \\
$7^{\text {b }}$ & RNAP-NusA-N-NusB-S10-nut \\
$8^{\text {b }}$ & RNAP-NusA-N-NusB-S10-NusG-nut
\end{tabular}

a/RNAP) RNA polymerase.

${ }^{\mathrm{b}}$ These complexes have indistinguishable mobilities.

fifth nucleotide of $\operatorname{box} B$ on the binding of $\mathrm{N}$, perhaps as a consequence of using different buffer conditions in their experiments. Mutating the corresponding nucleotide in the loop of boxB of the nutL site had a dramatic effect on the binding of an $\mathrm{N}$ peptide in buffer conditions that were similar to ours (Tan and Frankel 1995). Mutating the second or fourth nucleotide in the loop of box $B$ did not noticeably compromise the interaction between $\mathrm{N}$ and the nut site RNA (lanes 7-9, 13-15).

It therefore seemed likely that the defect in antitermination caused by mutating the second or fourth nucleotide in the loop of box $B$ weakened an interaction between box $B$ and one of the other components of an $\mathrm{N}$-modified elongation complex. To test this idea, we examined the ability of NusA to bind to $\mathrm{N}$-nut site complexes containing wild-type and mutant sequences (Fig. 2C). NusA alone did not bind nut site RNA (see, e.g., Fig. $2 \mathrm{E}$, lane 2). Whereas NusA was able to form a complex with $\mathrm{N}$ and wild-type nut site RNA /complex 2 in lanes 4 and 5 of Fig. 2 Cl, it was unable to form a complex with $\mathrm{N}$ and nut sites containing mutations in loop positions 2 and 4 (lanes 9-10, 14-15). These results indicated, therefore, that the loop of $b o x B$ binds $\mathrm{N}$ and is also important for the assembly of NusA.

Because there is also genetic evidence that NusA might interact with boxA (Olson et al. 1982), we wanted to determine whether box $A$ had any effect on the binding of NusA to an $\mathrm{N}-$ nut site complex. Inversion of box $A$ had no effect on the binding of $\mathrm{N}$ but greatly impaired the ability of NusA to supershift an $\mathrm{N}$-nut site complex (Fig. 2D, cf. lanes $1-5$ and lanes $6-10$ ), suggesting that NusA may also interact with box $A$. To further assess the biological relevance of this interaction between NusA and the $\mathrm{N}$-nut site complex, we used the NusAl mutant protein in a gel mobility shift experiment. The nusA1 mutation prevents $\mathrm{N}$-mediated antitermination in vivo (Friedman and Baron 1974). Although the NusAl mutant protein still binds $\mathrm{N}$ (Greenblatt and Li 1981a), it failed to shift an N-nut site complex (Fig. 2E, cf. lanes 5-6 and $7-8$ ), suggesting that the nusA1 mutation (a leucine to arginine change) affects the ability of NusA to bind RNA. Thus, boxA facilitates the incorporation of NusA into an N-NusA-nut site complex, and this is probably dependent on a functional RNA-binding domain in NusA. These experiments suggest that NusA may link the box $A$ and box $B$ components of the $\lambda$ nut sites by interacting with both of them. The formation of this link may stabilize the association of $\mathrm{N}$ and NusA with RNA polymerase and/or signal other factors to join the elongation complex.

\section{The association of $N$ with RNA polymerase is dependent on NusA}

It has been shown previously that RNA is able to form a nonspecific binary complex with the core catalytic component of RNA polymerase. The RNA in such a complex is positioned such that nucleotides can be added to its $3^{\prime}$ end and such that it can be cleaved by the transcript cleavage factors GreA and GreB (Altmann et al. 1994). Thus, it is likely that the $3^{\prime}$ end of the RNA is associated with the catalytic center of the enzyme just as it would be in an elongating transcription complex (Altmann et al. 1994). Consistent with this observation, we found that the RNA polymerase core component was able to bind nut site RNA in the absence of any other factor (Fig. $3 \mathrm{~A}$, lane 2, complex 3). When increasing amounts of $\mathrm{N}$ were added to a reaction containing RNA polymerase and the nut site RNA, the amount of probe bound to RNA polymerase decreased substantially, and formation of the $\mathrm{N}$-nut site complex was detected (complex 1, lanes $3,4 \mid$. This competition between RNA polymerase and $\mathrm{N}$ for the nut site RNA almost certainly indicated that the nut site was positioned in the catalytic center of RNA polymerase and not positioned on RNA polymerase as it would have been in an $\mathrm{N}$-modified transcription complex. The absence of a complex containing N, RNA polymerase, and the nut site RNA suggested that they were unable to form a stable complex in the absence of other factors.

NusA is known to bind RNA polymerase (Greenblatt and Li 1981b), and consistent with this observation, we observed that NusA supershifted the RNA polymerasenut site complex 3 to form complex 4 \{Fig. 3A, lane 5\}. The addition of increasing amounts of $\mathrm{N}$ to complex 4 (lanes 6,7$)$ resulted in the formation of a lower mobility band (complex 5). Complex 2 was not observed in this experiment or in most subsequent experiments shown in Figures $4-7$ because it was not stable in the gel conditions that we used to detect complexes containing RNA polymerase. The failure of Chattopadhyay et al. (1995) to detect an N-NusA-nut site complex is most likely a result of the gel conditions they used. Because the addition of $\mathrm{N}$ to complex 4 would only increase its molecular weight by $2.5 \%$, the substantially lower mobility of complex 5 compared with complex 4 implies that the conformations of complexes 4 and 5 are quite different. Moreover, the formation of complex 5, but not complex 4, was strongly correlated with the ability of the nut site to function in antitermination (Fig. 3B). Thus, mutations in the loop of $\operatorname{box} B$ that affect either the ability of $\mathrm{N}$ to bind the nut site RNA or the ability of NusA to supershift an $\mathrm{N}-$ nut site complex impaired the formation of 
A

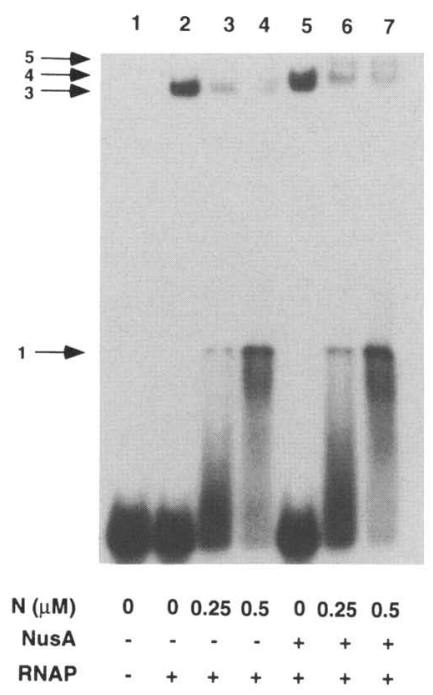

B

$\begin{array}{lllllllllllllll}2 & 3 & 4 & 5 & 6 & 7 & 8 & 9 & 10 & 11 & 12 & 13 & 14 & 15 & 16\end{array}$

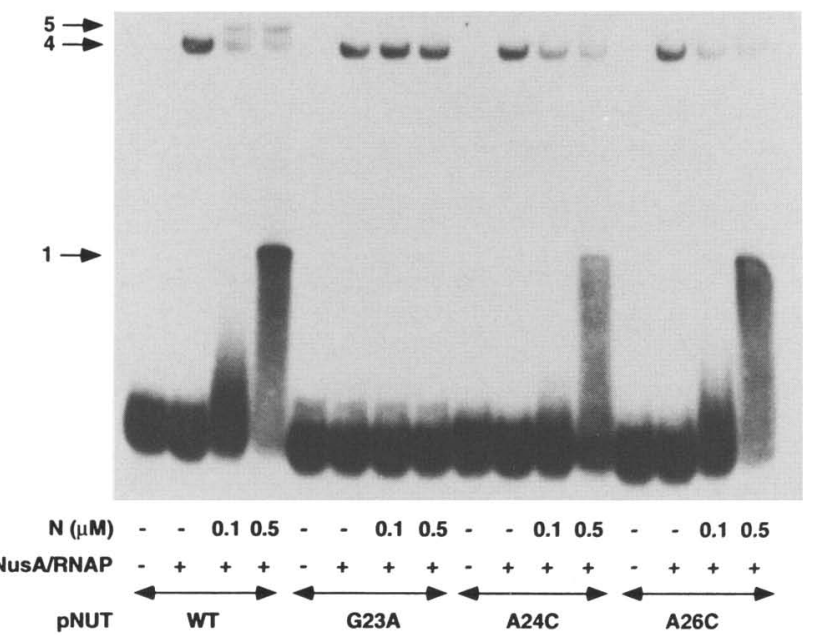

Figure 3. The stable association of $\mathrm{N}$ with RNA polymerase is dependent on NusA and boxB. (A) NusA facilitates the association of $\mathrm{N}$ with RNA polymerase. Various combinations of $\mathrm{N}$, NusA (100 nM) and RNA polymerase $(25 \mathrm{nM})$ were incubated with ${ }^{32} \mathrm{P}$-labeled wild-type nut site RNA and electrophoresed on a nondenaturing polyacrylamide gel. $(B)$ Mutations in the loop of $b o x B$ affect the assembly of complex 5 . Various combinations of N, NusA (100 nM) and RNA polymerase $(25 \mathrm{nM})$ were incubated with wild-type or mutant nut site RNA, as indicated, and electrophoresed on a nondenaturing polyacrylamide gel.

complex 5 (Fig. 3B, cf. lanes 3,4 and lanes 7,8, 11,12, $15,16)$. Presumably, the difference in conformations between complexes 4 and 5 exists because the nut site in complex 5 is no longer in the catalytic center. Therefore, the stable and specific association of $\mathrm{N}$ with an RNA polymerase-nut site complex is dependent on the presence of both NusA and wild-type boxB RNA.

\section{NusB, NusG, and S10 bind to complex 5}

To determine how the remaining Nus factors associate with a complex containing N, NusA, and RNA polymerase, we added various combinations of the proteins to complex 5 (Fig. 4A). On its own, NusG was able to create a new complex (complex 6 in lane 7). Neither NusB nor S10 alone was able to do so (lanes 5,6), but together they too were able to create a new complex with lower electrophoretic mobility (lane 8 , complex 7 ). This result is consistent with the observation that NusB and S10 form a heterodimer that is able to bind rm boxA RNA (Mason et al. 1992b; Nodwell and Greenblatt 1993). Unexpectedly, the assembly of NusG and NusB onto complex 5 was also highly cooperative (lane 9|, suggesting that NusB and NusG may also interact. There were also indications of weak cooperative binding for NusG and S10 (lane 10). Interactions of NusG with NusB and S10 may be too weak to have been detected in previous direct protein-protein binding experiments. Alternatively, these interactions could be indirect. Addition of all of the Nus factors to the binding reaction resulted in formation of the most stable complex (lane 11, complex 8) as judged by the quantity of probe shifted. The formation of complex 8 was specific, as it was impaired by mutations in box $B$ that affect the binding of $\mathrm{N}$ or NusA (data not shown). Although the formation of this complex was highly dependent on RNA polymerase, N, NusA, NusB, and NusG, the yield was only increased about two-fold by the presence of S10 (lanes 9 and 11); (see also Fig. 5B, lanes 7,9 ). Either S10 does not contribute greatly to the stability of the complete complex or the stabilizing effect of S10 may only be more evident if lower concentrations of other factors are used in the reactions.

We then determined the minimal set of factors required to assemble NusB, NusG, and S10 onto a nut site. NusB, NusG, and S10 were unable to supershift an N-NusA-nut site complex (data not shown). They were also unable to stably associate with an RNA polymerase-nut site complex (Fig. 4B, cf. lanes 2 and 3) or to supershift complex 4, which contains RNA polymerase and NusA (cf. lanes 4 and 5). NusB, NusG, and S10 were also unable to form a complex with N, RNA polymerase, and the nut site RNA in the absence of NusA (cf. lanes 6 and 7). As before, however, they were able to supershift complex 5 (cf. lanes 8 and 9). Therefore, the association of N, NusA, and RNA polymerase with the nut site is required for the assembly of NusB, NusG, and S10.

Because the concentration of RNA in these mobility shift experiments was $\sim 25-50 \mathrm{pm}$ and the concentrations of the proteins were mostly in the 25- to $100-\mathrm{nM}$ range, we considered the possibility that a minor contaminant in one of our protein preparations might be necessary for the observed mobility shifts. This seemed unlikely because mutations in the nut site and various proteins that interfere with function in vivo each affect the assembly of one or other of the various complexes 
A

$\begin{array}{lllllllllll}1 & 2 & 3 & 4 & 5 & 6 & 7 & 8 & 9 & 10 & 11\end{array}$

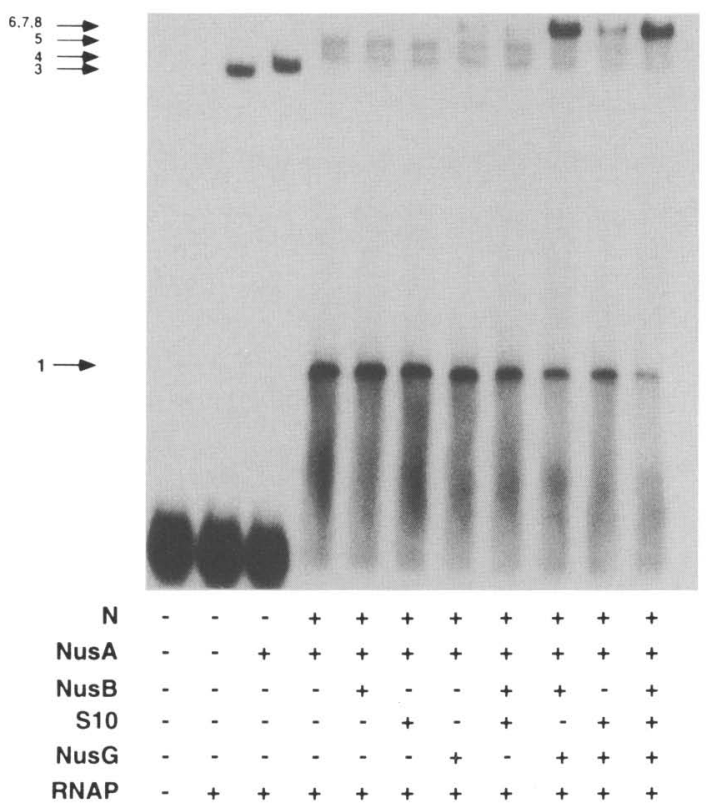

B

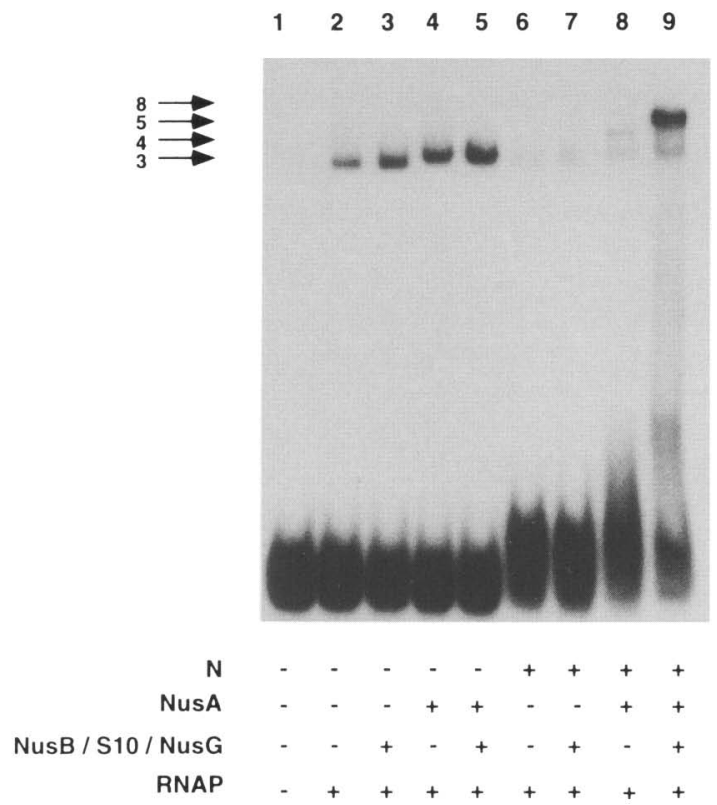

C
Figure 4. NusB, NusG, and S10 bind to complex 5. (A) NusB, NusG, and S10 assemble onto complex 5. Various combinations of $N(500 \mathrm{nM})$, NusA (100 nM), NusB (50 nM), NusG (50 nM), S10 (50 nM) and RNA polymerase (25 nM), as indicated, were incubated with ${ }^{32} \mathrm{P}$-labeled wild-type nut site RNA and electrophoresed on a nondenaturing gel. $(B)$ The formation of complex 5 is required for the assembly of NusB, NusG, and S10. Various combinations of N (500 nM), NusA (100 $\mathrm{nM})$, NusB (50 nM), NusG (50 nM), S10 (50 nM) and RNA polymerase (25 nM), as indicated, were incubated with ${ }^{32} \mathrm{P}$-labeled wild-type nut site RNA and electrophoresed on a nondenaturing gel. (C) N, NusA, NusB, NusG, and S10 associate with nut site RNA in the presence of RNA polymerase. Western blot analysis shows $50 \mathrm{ng}$ of the various proteins (lane 1) and the eluted proteins from streptavidin-agarose beads bound by nut site RNA in reactions that contained $\mathrm{N}$, RNA polymerase, NusA, NusB, NusG, and S10 (lane 4) or from beads that lacked nut site RNA (lane 2) or in reactions that lacked $N$ protein (lane 3).

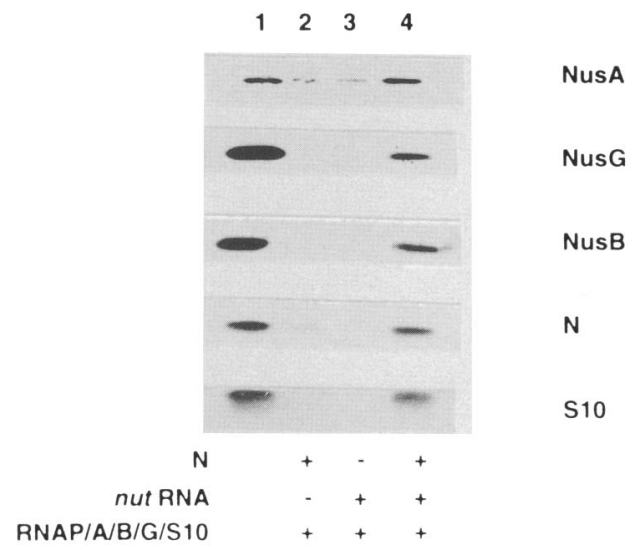

gel and detected by Western blotting (Fig. 4C). As controls, either nut site RNA or N protein was omitted from the reaction. Substantial amounts of N, NusA, NusB, NusG, and S10 were all present in eluates from beads when $\mathrm{N}$ and nut site RNA were both included in the reaction (lane 4). Only a trace amount of $\mathrm{N}$ bound nonspecifically to the beads (lane 2). As well, small amounts of NusA were present in both control eluates, probably reflecting the binding of NusA to RNA polymerase that had associated with the single-stranded DNA on the beads (lanes 2,3 ). In contrast, NusB, NusG, and S10 were not present in eluates derived from reactions that lacked either $\mathbf{N}$ or nut site RNA (lanes 2,3). Therefore, as predicted by the mobility shift assays, $\mathrm{N}$ and all four Nus factors can enter complexes on nut site RNA in the presence of RNA polymerase. However, although it seems 
B
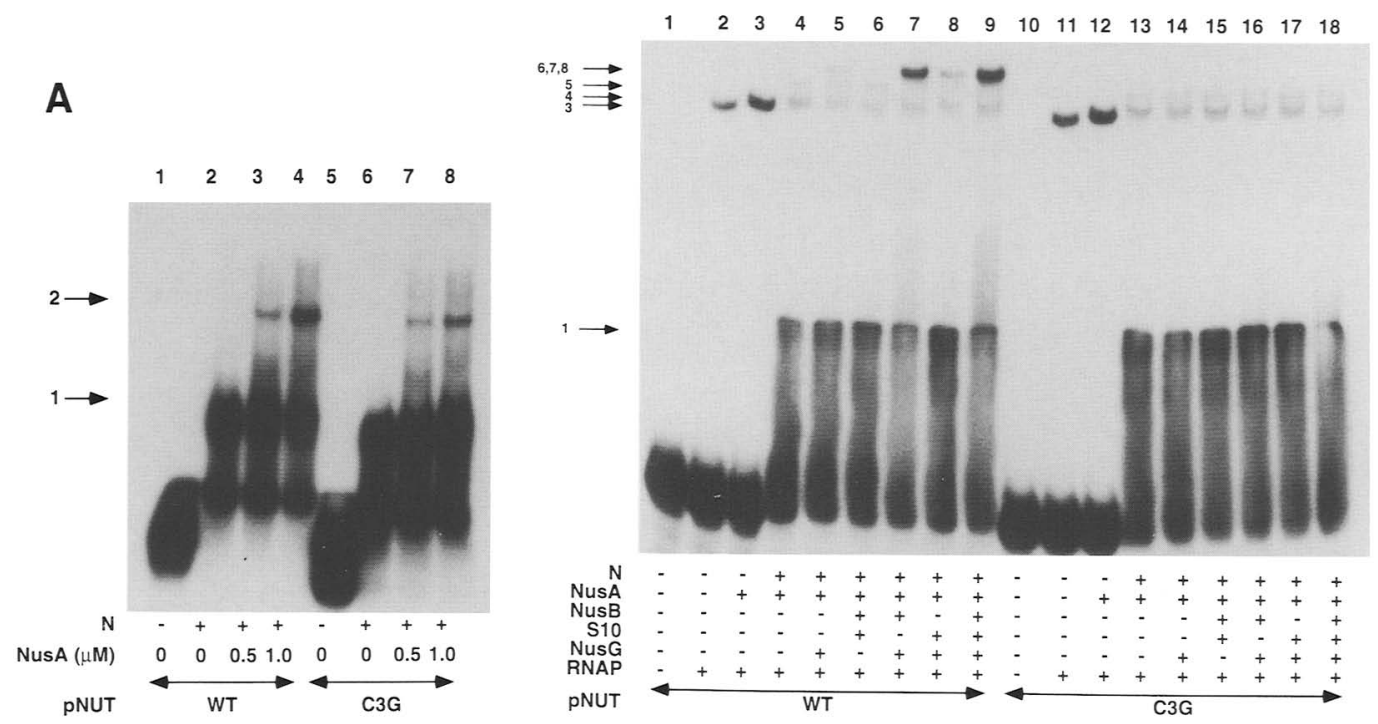

Figure 5. A point mutation in boxA affects the assembly of NusB, NusG, and S10. (A) The C3G mutation in boxA has little effect on the assembly of complex 2. Various combinations of $\mathrm{N}(1.5 \mu \mathrm{M})$ and NusA were incubated with ${ }^{32} \mathrm{P}$-labeled wild-type or mutant (pNUTC3G) nut site RNA, as indicated. The reactions were electrophoresed on a $7.5 \%$ nondenaturing polyacrylamide gel. $(B)$ The C3G mutation in boxA affects the assembly of NusB, NusG, and S10. Various combinations of $\mathrm{N}$ (500 nM), NusA (100 nM), NusB (50 nM), NusG $(50 \mathrm{nM}), \mathrm{S} 10(50 \mathrm{nM})$ and RNA polymerase $(25 \mathrm{nM})$ were incubated with ${ }^{32}$ P-labeled wild type or mutant (pNUTC3G) nut site RNA, as indicated, and electrophoresed on a nondenaturing polyacrylamide gel.

likely, we cannot be certain that $\mathrm{N}$ and all four Nus factors are present in the same complex.

boxA is important for the association of NusB, NusG, and S10 with complex 5

The rRNA operon $(r n)$ boxA binds a heterodimer of NusB and S10, whereas the $\lambda$ boxA is unable to do so (Nodwell and Greenblatt 1993). This suggests that the $\lambda$ box $A$ is a weaker version of the $\operatorname{rrn}$ boxA that requires additional factors to stably bind NusB and S10. We wanted to determine whether the association of NusB and S10 with complex 5 would be impaired by a mutation in boxA. To do so, we chose a mutation in boxA la $\mathrm{C} \rightarrow \mathrm{G}$ change at position 3 ) that interferes with antitermination in the rrn system (Berg et al. 1989) but had only a relatively small effect on the assembly of NusA onto an N-nut site complex (Fig. 5A, cf. lanes 1-4 and 5-8). As well, this mutation did not affect the assembly of complex 5 (Fig. 5B, cf. lanes 4 and 13). This point mutation did, however, impair the assembly of NusB and S10 (cf. lanes 6 and 15). Unexpectedly, the formation of all of the complexes higher than complex 5 was compromised /cf. lanes 5-9 and 14-18), demonstrating that the binding of NusG to complex 5 is also affected by a point mutation in boxA. This result indicates that NusG may interact with box $A$ directly or indirectly through NusA.

Consensus boxA suppresses the effect of the nusAl mutation by facilitating the assembly of NusB

As the mutations we have tested in the nut site and
NusA that compromise antitermination weaken interactions among particular components of the $\mathrm{N}$-modified complex, a mutation that increases the efficiency of antitermination could strengthen interactions within the complex. Because consensus boxA can suppress the effects on antitermination of the nusA1 and nusE71 mutations in vivo (Friedman et al. 1990), we wanted to determine whether consensus box $A$ could facilitate the incorporation of NusAl into complex 2. Figure 6A demonstrates that this is not the case (cf. lanes 9,10 and 11,12 ). In fact, changing the box $A$ sequence to the consensus sequence did not detectably stabilize the association of NusA with an N-nut site complex (cf. lanes 3,4 and 9,10$)$.

This suggested that consensus box $A$ strengthens another interaction that allows the stable association of NusAl with the transcription complex. To identify this interaction, we examined the assembly of NusB, NusG, and $\mathrm{S} 10$ onto a consensus boxA-containing complex 5 (N-NusA-RNA polymerase-nut site). Figure 6B demonstrates that NusB alone associated strongly with this complex 5 (cf. lanes 5 and 14), whereas S10 alone did so only very weakly (cf. lane 6 and 15). Although the assembly of NusG was slightly facilitated by consensus box $A$ (cf. lanes 7 and 16), the increased assembly of NusB was most dramatic. As expected, however, from the inability of NusB to bind $\operatorname{rrn}$ boxA in the absence of $S 10$ or other proteins (Nodwell and Greenblatt 1993), the assembly of NusB still needed other proteins and, in the absence of S10, depended on the formation of complex 5 (data not shown). 
A

C

$\begin{array}{llllllllllll}1 & 2 & 3 & 4 & 5 & 6 & 7 & 8 & 9 & 10 & 11 & 12\end{array}$

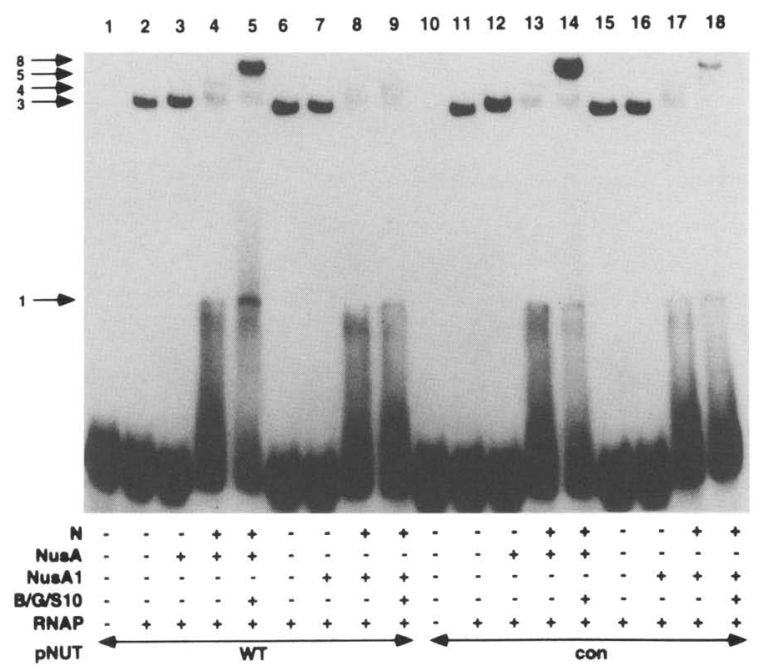

B
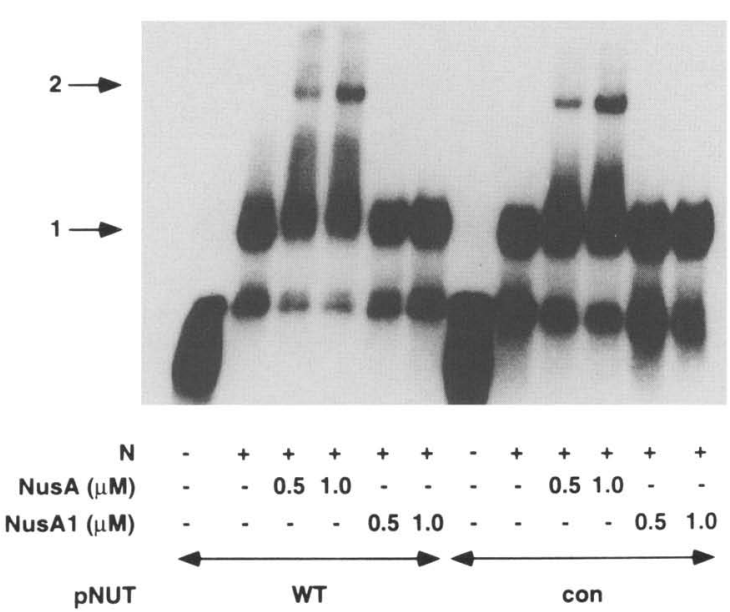

$\begin{array}{llllllllllllllllll}1 & 3 & 4 & 5 & 6 & 7 & 8 & 9 & 10 & 11 & 12 & 13 & 14 & 15 & 16 & 17 & 18\end{array}$

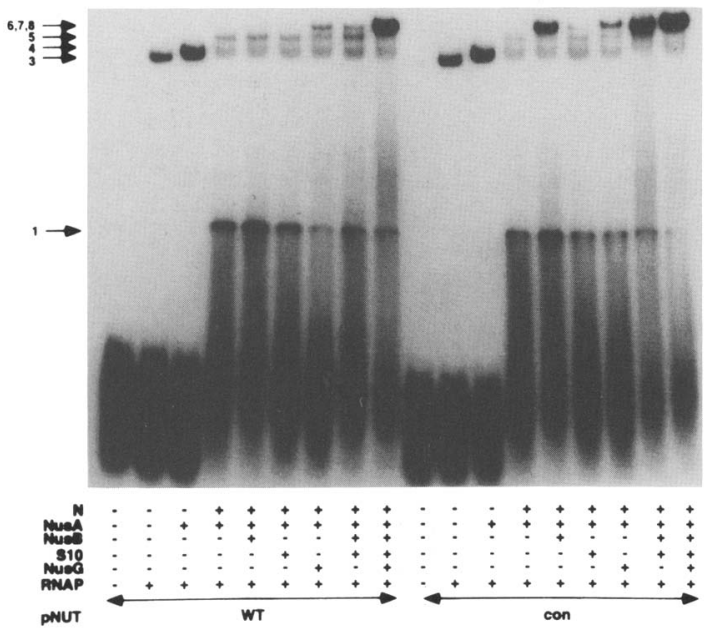

Figure 6. Consensus boxA facilitates the assembly of NusAl through a strengthened interaction with NusB. $(A)$ Consensus box $A$ is unable to facilitate the assembly of the NusAl mutant protein onto an $\mathrm{N}$-nut site complex. Various combinations of $\mathrm{N}(1.5 \mu \mathrm{M}), \mathrm{NusA}$, and NusAl were incubated with ${ }^{32} \mathrm{P}$-labeled wild-type or consensus boxA-containing nut site RNA, as indicated. The reactions were electrophoresed on a $7.5 \%$ nondenaturing polyacrylamide gel. $(B)$ Consensus box $A$ facilitates the assembly of NusB. Various combinations of $N(500 \mathrm{nM})$, NusA (100 nM), NusB (100 nM), NusG (50 nM), S10 (100 nM) and RNA polymerase (25 nM) were incubated with ${ }^{32} \mathrm{P}$-labeled wild-type or consensus boxA-containing nut site RNA, as indicated. The reactions were electrophoresed on a nondenaturing polyacrylamide gel. $(C)$ Consensus box $A$ facilitates the assembly of NusA1. Various combinations of $\mathrm{N}$ (500 nM), NusA (100 nM), NusAl (100 nM), NusB (50 nM), NusG (50 nM), S10 (50 nM) and RNA polymerase $(25 \mathrm{nM})$ were incubated with ${ }^{32} \mathrm{P}$-labeled wild-type or consensus box $A$ containing nut site RNA, as indicated. The reactions were electrophoresed on a nondenaturing polyacrylamide gel.

We then determined whether consensus box $A$ was able to allow the formation of a complete $\mathrm{N}$-modified complex that contained NusAl. When a wild-type nut site was used, the nusA1 mutation greatly compromised the assembly of complexes 5 and 8 (Fig. 6C, cf. lanes 4,5 and lanes 8,9$)$. Consensus box $A$ substantially stabilized the assembly of complex 8 when wild-type NusA was used in the reactions (cf. lane 5 and 14) and also allowed the incorporation of the mutant NusAl protein into complex 8 (cf. lane 9 and 18). Thus, a strengthened interaction between consensus box $A$ and NusB is what most likely allows for the assembly of NusAl into an $\mathrm{N}$-modified transcription complex.

Mutations in RNA polymerase affect the assembly of NusG

The ron mutation in the $r p o B$ gene, which encodes the $\beta$-subunit of RNA polymerase, interferes with antitermination (Ghysen and Pironio 1972; Li et al. 1992). It also prevents the formation of a stable $\mathrm{N}$-modified elongation complex (Nodwell and Greenblatt 1991; Mason et al. 1992a). Figure 7A demonstrates that the ron mutation had little or no affect the assembly of complex 5 (cf. lanes 4 and 10), but strongly affected the assembly of NusG (cf. lanes 6,12), and had a weaker effect on the assembly of NusB and S10 (cf. lanes 5,11). RNA polymerase with the ron mutation was still, however, able to support the assembly of complex 8 , and the yield was only slightly lower than with wild-type RNA polymerase (cf. lanes 7 and 13). This observation is consistent with the mild phenotype of the ron mutation in vivo, where the growth of $\lambda$ is impaired by the ron mutation only if there is an additional mild mutation in the $N$ gene (Ghysen and Pironio 1972). The nature of an additional electrophoret- 
A

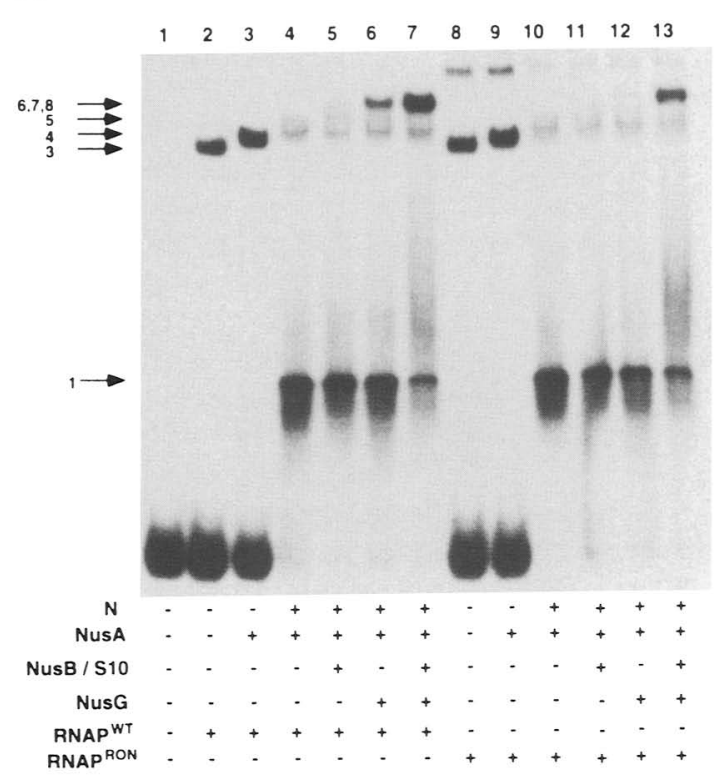

B

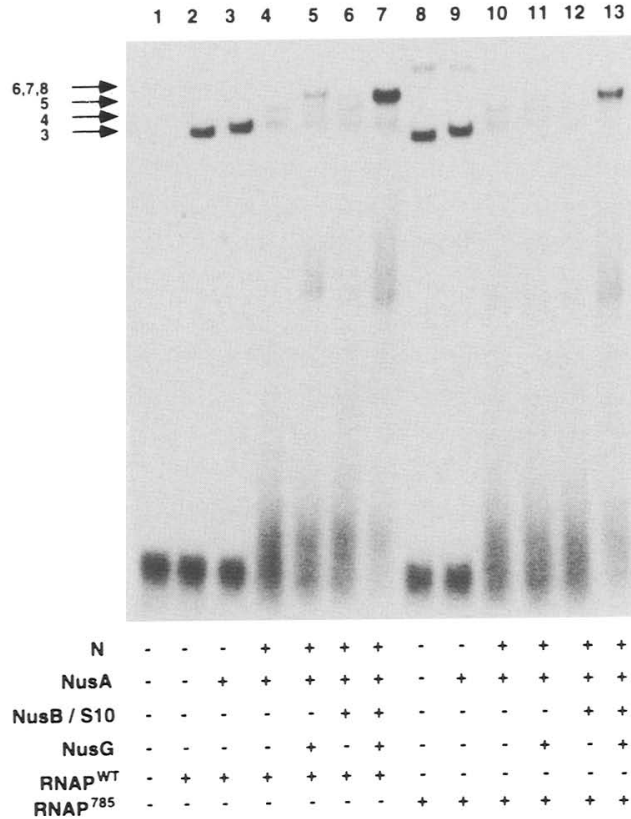

C $\begin{array}{lllllllllllllll}1 & 2 & 3 & 4 & 5 & 6 & 7 & 8 & 9 & 10 & 11 & 12 & 13 & 14 & 15\end{array}$

Figure 7. Mutations in RNA polymerase and NusA can affect the assembly of higher order complexes. $(A)$ The ron mutation in the $\beta$-subunit of RNA polymerase affects the assembly of higher order complexes. N (500 nM), NusA (100 nM), NusB (50 nM), NusG (50 nM), S10 $(50 \mathrm{nM})$, wild-type RNA polymerase (25 $\mathrm{nm}$ ) and ron RNA polymerase $(25 \mathrm{nM})$ were incubated in various combinations with ${ }^{32} \mathrm{P}$-labeled wildtype nut site RNA, as indicated, and electrophoresed on a nondenaturing polyacrylamide gel. (B) The groN785 mutation in the $\beta$-subunit of RNA polymerase affects the assembly of higher order complexes. N (500 nM), NusA (100 nM), NusB (50 nM), NusG (50 nM), S10 (50 nм), wild-type RNA polymerase ( $25 \mathrm{nM}$ ), and groN785 RNA polymerase (25 $\mathrm{nM}$ ) were incubated in various combinations, as indicated, with ${ }^{32} \mathrm{P}$ labeled wild-type nut site RNA and electrophoresed on a nondenaturing polyacrylamide gel. $(C)$ The nusA785 mutation affects the assembly of complex 8. Various combinations of $\mathrm{N}(500 \mathrm{nM}), \mathrm{NusA}(100 \mathrm{nM})$, NusA785 (100 nM), NusB (50 nM), NusG (50 nM), S10 (50 nM), wild-type RNA polymerase $(25 \mathrm{nM})$, and groN785 RNA polymerase $(25 \mathrm{nM})$ were incubated with ${ }^{32}$ P-labeled wild-type nut site RNA, as indicated. The reactions were electrophoresed on a nondenaturing polyacrylamide gel.

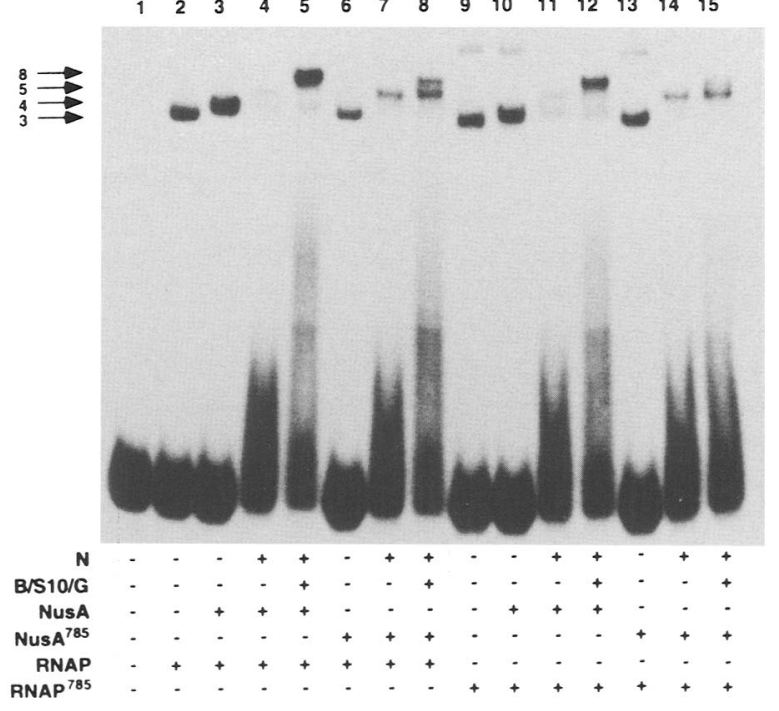

ic band observed when ron RNA polymerase was incubated with the nut site RNA (cf. lanes 2 and 8 ) is unclear.

The groN785 strain of $E$. coli was shown to contain mutations in $r p o B$, nusA, and nusE that resulted in a $\lambda$-resistance phenotype (Georgopoulos 1971, and pers. comm.; Greenblatt and Li 1981a). The groN785 mutation in $r p o B$ is necessary, but not sufficient, to confer $\lambda$ resistance. As in the case of the ron mutation, the groN785 mutation affected the assembly of complexes 6, 7, and 8 (Fig. 7B, cf. lanes 5-7 and 11-13), and again, the effect on the assembly of NusG was particularly striking (cf. lanes 5 and 11). Next we determined whether the nusA785 mutation compounded the assembly defect of the rpoB 785 mutation. Figure $7 \mathrm{C}$ demonstrates that the
nusA785 mutation interfered substantially with the assembly of complex 8 (cf. lanes 5 and 8 ). Also, it further destabilized the groN785 RNA polymerase-containing complex 8 (cf. lanes 12 and 15). Thus, mutations in the $\beta$-subunit of RNA polymerase and NusA can affect the assembly of complexes 6-8.

\section{Discussion}

We have used gel mobility shift and in vitro binding assays to analyze binding of the $\lambda \mathrm{N}$ protein, $E$. coli RNA polymerase, and four $E$. coli Nus factors to a $\lambda$ nut site RNA. At least in vitro the assembly of these factors onto the nut site can be a highly ordered process. Surprisingly, 
the assembly of a complete antitermination complex on RNA polymerase does not depend on the presence of a DNA template. As a consequence, such an analysis provides a great deal of information about the protein-protein and protein-RNA interactions, which are important for the overall stability of the complex. The known protein-protein and protein-RNA interactions defined previously or in these experiments are shown as solid lines in Figure 8A. These and inferred interactions predicted by the results of our gel mobility shift assays or by previous genetic studies (broken and dotted lines in Fig. 8A) form a remarkably complex web. A striking feature of this network of interactions is that each element of the network has multiple interactions with other elements of the network. This presumably explains why assembly of the complete complex is a highly cooperative process (Horwitz et al. 1987; Mason and Greenblatt 1991; Nodwell and Greenblatt 1991).

Lazinski et al. (1989) showed that the nut sites of the lambdoid phages are selectively recognized by the arginine-rich amino-terminal portions of their respective $\mathrm{N}$ proteins. We have directly shown here that the loop of box $B$ is important for the binding of $\mathrm{N}$ to the nut site RNA. Surprisingly, however, nucleotides 2 and 4 in the box $B$ loop seem unimportant for the binding of $\mathrm{N}$ and, instead, critically affect the binding of NusA to the $\mathrm{N}$-nut site complex. On the basis of their observation that the alteration of $\lambda$ box $A$ to a consensus boxA element suppressed the effect of the nusA1 mutation, Friedman and his collaborators suggested that NusA ought to recognize boxA (Schauer et al. 1987; Friedman et al. 1990). In the experiments described here and in experiments with various other boxA mutants (T. Mah, unpubl.), we have found that the stable association of NusA with the $\mathrm{N}-n u t$ site complex requires boxA. Nevertheless, NusA can bind to the $\mathrm{N}-n u t$ site complex in the absence of boxA when the reactions contain higher concentrations of NusA (data not shown). Because box $A$ is not essential for antitermination over short distances (Peltz et al. 1985; Zuber et al. 1987; Patterson et al. 1994) and NusA is still necessary in these circumstances $(\mathrm{Zu}-$ ber et al. 1987; Whalen et al. 1988; Mason et al. 1992a; Patterson et al. 1994), the NusA-boxA interaction most likely plays a role in stabilizing the $\mathrm{N}$-modified transcription complex. However, the direct effect of altering box $A$ to a consensus element is to stabilize the binding of NusB rather than NusA. Thus, the ability of consensus boxA to reverse the effect of the nusA1 mutation is an indirect one that operates through NusB. This is not particularly surprising because the consensus box $A$ sequence can also suppress the effect of the nuSE71 mutation in the ribosomal protein S10 (Friedman et al. 1990). This importance of box $A$ for the assembly of NusB can explain why nonprocessive antitermination at $t_{R_{1}}$ just downstream from nut $R$ requires neither box $A$ nor NusB (Patterson et al. 1994).

The inability of NusA to bind to the nut site in the absence of $\mathrm{N}$ provides further evidence for a direct interaction between $\mathrm{N}$ and NusA (Greenblatt and Li 1981a). The inability of NusAl protein to bind an N-nut com- plex in spite of the normal affinity of the NusA1 protein for N (Greenblatt and Li 1981a; J. Greenblatt and J. Li, unpubl.) suggests that the nusA1 mutation is in an RNAbinding region of NusA. This idea is strengthened by the fact that nusA1 is a leucine-to-arginine change in an arginine-rich region of NusA (Craven et al. 1994): Argininerich domains have been implicated in RNA-binding in $\mathrm{N}$, the Tat protein of HIV-1, and many other proteins (for review, see Lazinski et al. 1989).

The importance of both box $A$ and $\operatorname{box} B$ for the binding of NusA to the $\mathrm{N}-$ nut site complex suggests either that NusA recognizes box $A$ and $\operatorname{box} B$ separately or that NusA recognizes and stabilizes a folded structure comprised of both of these elements. At least two such folded structures are conceivable (see Fig. 8B): One would involve a pseudoknot in which $\mathrm{U}$ residues in box $A$ (CGCUCUUAC) would pair with A residues in the loop of box $B$ (GAAAA); the other, suggested to us by $M$. Gottesman (Columbia University, New York), would involve unwinding of the stem of boxB to form a new base-paired structure involving residues near the $5^{\prime}$ end of box $A$. In either case, mutating box $A$ to consensus would introduce an extra $U$ residue (CGCUCUUUA) and allow an additional base pair to form, perhaps explaining why consensus box $A$ is "stronger" than wild-type box $A$.

In our experiments $\mathrm{N}$ and RNA polymerase could not bind simultaneously to the nut site RNA in the absence of NusA. This was probably the case because RNA polymerase can only bind RNA in the same manner as a nascent transcript when it can place the $3^{\prime}$ end of its transcript at its catalytic center (Altmann et al. 1994). In this case, the $3^{\prime}$ end of the transcript was only 9 nucleotides downstream from $\operatorname{box} B$, and $\operatorname{box} B$ was already occupied by $\mathrm{N}$. Therefore, the $\mathrm{N}-n u t$ site complex presumably could only associate with RNA polymerase in the manner of an antiterminator element, not as an ordinary nascent transcript, and this was possible only in the presence of NusA, which itself directly binds RNA polymerase (Greenblatt and Li 1981b). In contrast, Chattopadhyay et al. (1995) detected a complex that contains only N, RNA polymerase, and nut site RNA. It is likely that $b o x B$ was far enough away from the $3^{\prime}$ end of the RNA used in their experiments to allow $\mathrm{N}$ and the catalytic center of RNA polymerase to bind independently and simultaneously to the transcript.

NusA can bind both $\mathrm{N}$ and the elongating core component of RNA polymerase (see Fig. 8A; Greenblatt and Li 1981a,b; Horwitz et al. 1987). In our mobility shift experiments, NusA could be made to associate first with $\mathrm{N}$ on the nut site RNA and only then with RNA polymerase, or vice versa, as illustrated in Figure 8C. It is not clear which pathway for the association of NusA would be favored in vivo.

Only in the presence of complex 5 containing $\mathrm{N}$, NusA, and RNA polymerase could we observe the binding of NusB, NusG, and S10. Western blotting showed that $\mathrm{N}$ and all four host factors can assemble onto the nut site RNA, although we have not formally proved that all of these proteins are simultaneously present in a single complex. The instability and consequent low 


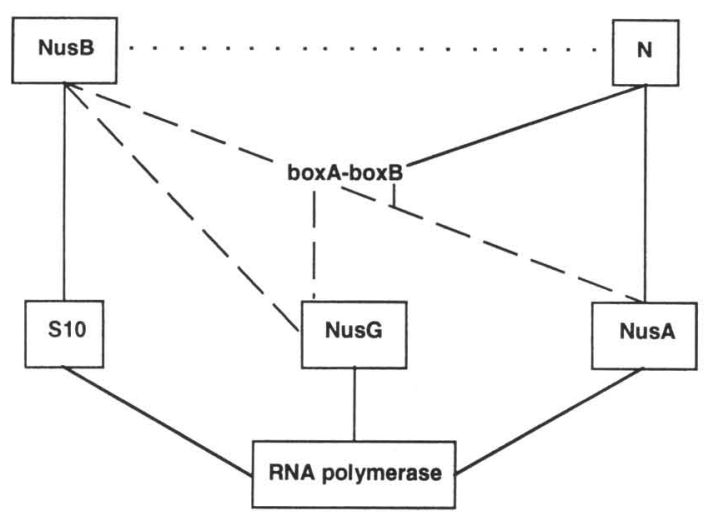

C
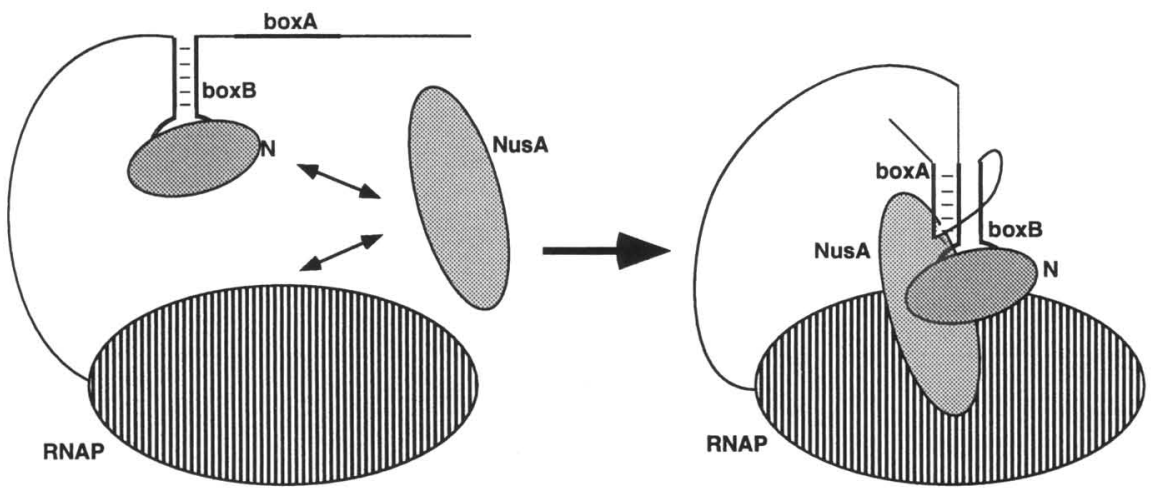

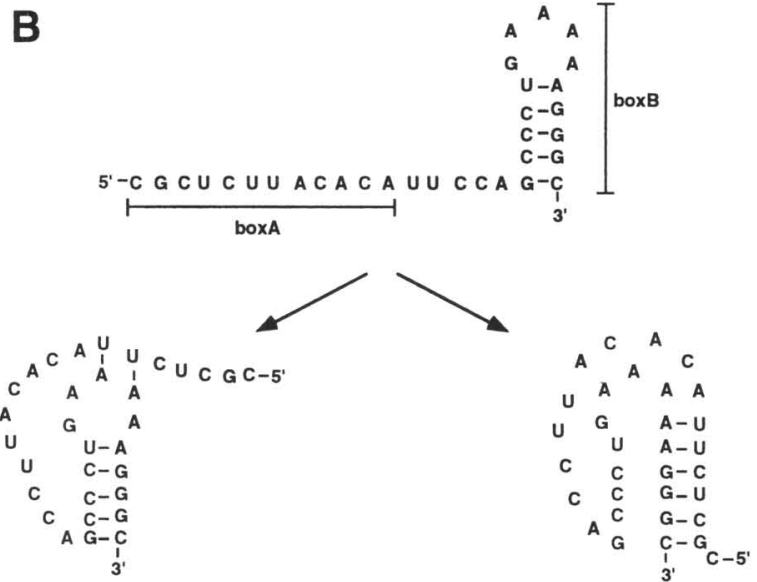

D

Figure 8. Models for the cooperative assembly of an N-modified elongation complex. (See text for details.) (A) Protein-protein and protein-RNA interactions involved in the formation of a stable antitermination complex. Solid lines denote direct interactions that have been characterized biochemically (Greenblatt and Li 1981a,b; Mason and Greenblatt 1991; Das 1992; Li et al. 1992; Mason et al. 1992b; Nodwell and Greenblatt 1993). Broken lines denote interactions defined indirectly on the basis of the gel mobility shift assays described here. The dotted line denotes an N-NusB interaction for which there is genetic evidence (Ward et al. 1983). (B) Two possible folded structures for the nut site RNA. (C) Pathways for the assembly of N, NusA, and RNA polymerase onto a folded nut site. (D) Pathways for the assembly of NusB, NusG, and S10. This diagram is an interpretation of the data in Figs. 5, A and B, and 7B. (R) RNA polymerase; (A) NusA; (B) NusB; (G) NusG; (S) S10.

yield of complex 5 have prevented us from formally proving that complex 5 is a precursor of complexes $6-8$, but that is likely to be so because complex 5 usually disappears in the presence of NusB, NusG, and S10 (see, e.g., Fig. 6C, lanes 5,14) and because mutations in box $B$ interfere with the formation of complexes 5 and 8 (Fig. 3B; data not shown). Again, several pathways for the binding to complex 5 of NusB, NusG, and S10 were possible (see Fig. $8 \mathrm{D} \mid$, and it is not clear which one occurs in vivo. However, it is very striking that the assembly on RNA polymerase of a complete complex containing $\mathrm{N}$, all four Nus, factors, and nut site RNA does not require a DNA template.

As predicted by the effects of $\operatorname{rrn}$ boxA mutations (Nodwell and Greenblatt 1993), similar mutations in $\lambda$ box $A$ tested here and in other experiments (J. Mogridge and T. Mah, unpubl.) prevented the binding of NusB and S10. The ability of NusB to bind complex 5 in the absence of $\mathrm{S} 10$ when complex 5 contains a consensus box $A$ element implies that it is most likely NusB rather than S10 that directly binds boxA RNA. Although this effect of consensus $\operatorname{box} A$ on the binding of NusB could be indirect, it is consistent with the observation that NusB is titrated when consensus boxA RNA is overproduced in E. coli (Friedman et al. 1990).

An unexpected finding was the importance of $b o x A$ for the stable binding of NusG. Nevertheless, the ability of the C3G mutation in boxA to prevent the binding of both NusG and the NusB/S10 complex does not necessarily imply that the $\mathrm{C} 3$ nucleotide of $\operatorname{box} A$ is $\operatorname{directly}$ bound by NusG and NusB/S10. In each case, the C3G mutation may exert an indirect effect by altering the secondary or tertiary structure of boxA. Once NusG is bound in a manner that critically depends on box $A$, it dramatically facilitates the binding of NusB and possibly S10. One possibility, as illustrated in Figure 8A, is that NusG interacts with NusB, as well as with RNA polymerase (Li et al. 1992) and boxA. Stabilization of the binding of NusB could well explain why the nus $G 4 \mathrm{mu}$ tation suppresses nusA1 (Sullivan et al. 1992). In that case, the NusB-NusG interaction might have gone un- 
detected in direct binding experiments ( $\mathrm{Li}$ et al. 1992, 1993; Mason et al. 1992b) simply because it is very weak. However, it is also possible that NusG alters the conformation of box $A$ in such a way as to facilitate the binding of NusB and S10 to boxA.

It is striking that all of the mutations we have tested that compromise antitermination in vivo also block one or more steps in the assembly of an $\mathrm{N}$-modified complex. In particular, we have shown that assembly defects are caused by mutations in $\operatorname{box} A, \operatorname{box} B$, nus $A$, and $r p o B$. All of the mutations apparently affect the stability of the complex, as all the assembly reactions were incubated for $30 \mathrm{~min}$ and kinetic experiments (data not shown) have indicated that the assembly processes are completed in $<5$ min when wild-type proteins and RNA are used in the reactions. One particularly interesting phenomenon is the strong effects of the ron and groN785 mutations in $r p \circ B$ on the binding of NusG. These mutations may affect a NusG-binding site on the $\beta$-subunit of RNA polymerase. The gel mobility shift assays we have described here can now be used to systematically analyze the effects on assembly of mutations in box $A$, NusA, and RNA polymerase.

Why consensus box $A$ suppresses the nusA 1 mutation by facilitating the assembly of NusB requires further explanation. One possibility derives from the observation that mutations in nusB that suppress nusA1 for the $\mathrm{N}$ proteins of phages $\lambda$ and 21 are $N$ protein specific (Ward et al. 1983). This may imply that NusB interacts with $\mathrm{N}$ (see Fig. 8A). Therefore, NusB that is bound directly to consensus boxA and indirectly, via S10, to RNA polymerase (Mason and Greenblatt 1991) may stabilize the binding of $\mathrm{N}$ which, in turn, would facilitate the binding of the NusAl protein. This sort of indirect suppression mechanism probably also explains why there are nusA1suppressing mutations in $N$, nus $G$, and $r p o B$ (Friedman et al. 1990; Ward et al 1983; Sparkowski and Das 1992; Sullivan et al. 1992), as well as in boxA and nusB. This kind of phenomenon could well be a consequence of the complicated web of weak interactions that stabilize the $\mathrm{N}$-modified transcription complex (see Fig. 8A). Similar, complicated protein-protein and protein-nucleic acid interaction networks, as well as non-allele-specific suppression phenomena, may also turn out to be characteristic of other multiprotein complexes involved in transcriptional initiation by RNA polymerase 1 (Zawel and Reinberg 1993), RNA splicing (Horowitz and Krainer 1994), and other macromolecular processes (Stillman 1994; Aboussekhra et al. 1995).

\section{Materials and methods}

Plasmids, enzymes, and strains

NusA, NusB, NusG, N, and the core component of RNA polymerase were purified as described previously (Burgess and Jendrisak 1975; Geenblatt et al. 1980; Greenblatt and Li 1981b; Swindle et al. 1988; Li et al. 1992). Purified S10 was generously provided by Dr. Volker Nowotny (Max-Planck Institut für Molekulare Genetik, Berlin, Germany). All plasmids used for in vitro transcription were prepared in the bacterial strain $\mathrm{DH} 5 \alpha$
(Bethesda Research Laboratories) and purified on Qiagen-tip 500 columns (Qiagen). The oligonucleotides used for cloning into pTZ19R, for site-directed mutagenesis and the in vitro binding assay, were purchased from the HSC/Pharmacia Biotechnology Service Centre in Toronto. RNAguard was bought from Pharmacia. Restriction enzymes and DNA ligase were purchased from New England Biolabs. T7 RNA polymerase was obtained from BRL.

\section{Construction of pNUT Plasmids}

The following DNA oligonucleotides were synthesized: $\{1\} 5^{\prime}$ CGCTTCCCGCTCTTACACATTCCAGCCCTAAAAAAGGGCATCAG-3'; (2) 5'-AGCTTCCCGCTCTTACACATTCCAGCCCTGCAAAAGGGCATCAG-3'; (3) 5'-AGCTTCCCGCTCTTACACATTCCAGCCCTGACAAAGGGCATCAG3'; (4) $5^{\prime}$-AGCTTCCCGCTCTTACACATTCCAGCCCTGAACAAGGGCATCAG-3'; (5) 5'-AGCTTCCCGCTCTTACACATTCCAGCCCTGAAACAGGGCATCAG-3'; (6) 5' -TCGACTGATGCCCTTTTTCAGGGCTGGAATGTGTAAGAGCGGGA3'; (7) 5'-AGCTTCCACCTTACACATTCTCGCGCCCTGAAAAAGGGCATCAG-3'; (8) 5'-TCGACTGATGCCCTTTTTCAGGGCGCGAGAATGTGTAAGGTGGA3'. Oligonucleotides 1-5 were each annealed with oligonucleotide 6 to make plasmids pNUTG23A, A24C, A25C, A26C, and A27C, respectively. Oligonucleotides 7 and 8 were annealed to make pNUTrev $1-17$. The annealed oligonucleotides were cloned into the plasmid pTZ19R cut with HindIII and SalI. pNUTWT and pNUT mutants were identified using double-stranded DNA sequencing (Hsiao 1991).

\section{Site-directed mutagenesis of pNUTWT}

Preparation of single-stranded DNA was performed by transforming CJ236 (Ausubel et al. 1987) with pNUTWT plasmid DNA and growing in the presence of $100 \mu \mathrm{g} / \mathrm{ml}$ of ampicillin. Cells were infected with R408 and single-stranded DNA was isolated. Mutagenic oligonucleotides $(1 \mu \mathrm{g})$ were hybridized to dUMP-substituted DNA ( 1 pmole) in $10 \mu$ l reactions containing ligation buffer by heating the reaction in a boiling water bath for 5 min and allowing the bath to cool to room temperature. Annealed DNA was mixed with $10 \mu \mathrm{l}$ of extension/ligation mix (ligation buffer, $1 \mathrm{mM}$ ATP, $1 \mathrm{mM}$ dATP, $1 \mathrm{mM}$ dCTP, $1 \mathrm{mM}$ dGTP, $1 \mathrm{~mm}$ dTTP, $1 \mathrm{U} / \mu \mathrm{l}$ of DNA ligase, $0.2 \mathrm{U} / \mu \mathrm{l}$ of T4 DNA polymerase) and incubated at room temperature for $4 \mathrm{hr}$. Reaction mixtures $(5 \mu \mathrm{l})$ were transformed into $50 \mu \mathrm{l}$ of competent DH5 $\alpha$ cells. Colonies were picked and grown in overnight cultures, and plasmids were isolated by minipreparation (Ausubel et al. 1987). Positive clones were identified by using double-stranded DNA sequencing (Hsiao 1991). Oligonucleotides 5'-CCGCTCTTTAACATTCCA-3' and 5'-AAGCTTCCCGGTCTTACACATTC-3' were used to make pNUTcon and pNUTC3G, respectively.

\section{In vitro transcription and RNA purification}

${ }^{32} \mathrm{P}$-Labeled RNA for gel mobility shift experiments was produced in $10 \mu \mathrm{l}$ reactions containing $1 \times \mathrm{BRL}$ T7 RNA polymerase buffer, $5 \mathrm{~mm}$ dithiothreitol, $20 \mu \mathrm{Ci}$ of $\left[\alpha^{-32} \mathrm{P}\right] \mathrm{UTP}$ (NEN), $8 \mu \mathrm{M}$ UTP, $500 \mu \mathrm{M}$ ATP, CTP, and GTP, $1 \mathrm{U} / \mu \mathrm{l}$ of RNAguard, 50 $\mu \mathrm{g} / \mathrm{ml}$ of Sall-cut plasmid DNA, and $1.5 \mathrm{U} / \mu \mathrm{l}$ of T7 RNA polymerase. The reactions were incubated at $37^{\circ} \mathrm{C}$ for $4 \mathrm{hr}$. Five microliters of $95 \%$ deionized formamide, $0.05 \%$ bromophenol blue, and $0.05 \%$ xylene cyanol were added to the reactions, which were then incubated in a boiling water bath for $2 \mathrm{~min}$ and loaded on a $15 \%$ (37.5:1 acrylamide/bis) polyacrylamide/7 M 
urea gel and electrophoresed until the bromophenol blue had migrated two-thirds of the way down the gel. The labeled RNA was located by autoradiography; the gel slice containing the RNA was cut out and soaked in DEPC-treated water overnight. The yield of RNA was determined by liquid scintillation counting. ${ }^{3} \mathrm{H}$-Labeled RNA for in vitro binding assays was produced in $20 \mu \mathrm{l}$ reactions containing $1 \times$ BRL T7 RNA polymerase buffer, $5 \mathrm{mM}$ dithiothreitol, $0.5 \mu \mathrm{Ci} \alpha-{ }^{3} \mathrm{H}$-labeled UTP (NEN), $500 \mu \mathrm{M}$ UTP, ATP, CTP, and GTP, $1.5 \mathrm{U} / \mu \mathrm{l}$ of RNAguard, $50 \mu \mathrm{g} / \mathrm{ml}$ of SalI-cut plasmid DNA, and $2.5 \mathrm{U} / \mu \mathrm{l}$ of T7 RNA polymerase. RNA was gel purified as described above, except that it was visualized using UV shadowing. The RNA was then ethanol precipitated, resuspended in DEPC-treated water, and quantitated by liquid scintillation counting. These RNAs used in mobility shift assays and in vitro binding assays were 54 nucleotides long and contained the nutR site at positions 14-45. The complete sequence of the RNA containing the wild-type nut site is $5^{\prime}$-AGGGAAAGCUUCCCGCUCUUACACAUUCCAGCCCUGAAAAAGGGCAUCAGUCGA-3'.

\section{Gel mobility shift experiments}

$\mathrm{N}$, NusA, NusB, NusG, S10, and RNA polymerase (concentrations indicated in figures and figure legends) were incubated in $15-\mu$ l reactions with $\sim 2000 \mathrm{cpm}$ of ${ }^{32} \mathrm{P}$-labeled RNA (25-50 pM) in the presence of $40 \mathrm{mM}$ HEPES (pH 7.2), $20 \mathrm{~mm}$ ammonium sulfate, $15 \mathrm{~mm}$ potassium acetate, $10 \%$ glycerol (vol/vol), 55 $\mu \mathrm{g} / \mathrm{ml}$ of yeast tRNA, and $0.5 \mathrm{mg} / \mathrm{ml}$ of bovine serum albumin (BSA) for $30 \mathrm{~min}$ at $4^{\circ} \mathrm{C}$. The reactions were then loaded onto a gel containing 5\% (37.5:1 acrylamide/bis) polyacrylamide (unless otherwise indicated), $2 \%$ glycerol (vol/vol) and $0.5 \times$ Tris/ borate/EDTA between lanes loaded with bromophenol blue and xylene cyanol. The gel was run at $4^{\circ} \mathrm{C}$ and $23 \mathrm{~mA}$ until the bromophenol blue almost reached the bottom of the gel. The gel was dried and exposed to $\mathrm{x}$-ray film (Kodak XAR-5) with two intensifier screens at $-70^{\circ} \mathrm{C}$ overnight.

\section{In vitro binding assay}

Wild-type nut site RNA (200 ng) was incubated with $1 \mu \mathrm{g}$ of the 3' biotinylated DNA oligonucleotide, 5'-GAAGCTTTCCCTATAGTGAGTCGTATT- $3^{\prime}$, in the presence of $10 \mathrm{~mm}$ Tris, 10 mM magnesium sulfate, and $100 \mathrm{~mm}$ sodium chloride. The mixture was boiled and cooled to room temperature and then added to $10 \mathrm{mg}$ of streptavidin beads (BRL) and rotated at $4^{\circ} \mathrm{C}$ for $2 \mathrm{hr}$. The beads were washed twice with $100 \mu \mathrm{l}$ of $40 \mathrm{~mm}$ HEPES ( $\mathrm{pH}$ 7.2), $20 \mathrm{~mm}$ ammonium sulfate, $15 \mathrm{~mm}$ potassium acetate, 10 $\mathrm{mm}$ magnesium sulfate, $10 \%$ glycerol (vol/vol), and $0.5 \mathrm{mg} / \mathrm{ml}$ of BSA. The beads were then incubated with $100 \mathrm{nM}$ RNA polymerase, $330 \mathrm{~nm} \mathrm{~N}, 200 \mathrm{~nm}$ NusA, $200 \mathrm{~nm}$ NusB, $100 \mathrm{~nm}$ NusG, $170 \mathrm{nM} \mathrm{S10}$, and $75 \mu \mathrm{g} / \mathrm{ml}$ of yeast tRNA in a total volume of 60 $\mu l$ and were rotated at $4^{\circ} \mathrm{C}$ for $30 \mathrm{~min}$. The beads were washed three times with $150 \mu \mathrm{l}$ buffer containing $40 \mathrm{mM}$ HEPES $(\mathrm{pH}$ $7.21,20 \mathrm{~mm}$ ammonium sulfate, $15 \mathrm{~mm}$ potassium acetate, 10 $\mathrm{mM}$ magnesium sulfate, and $10 \%$ glycerol (vol/vol) and eluted with $40 \mu \mathrm{l}$ of $10 \mathrm{~mm}$ Tris, $1 \mathrm{~mm}$ EDTA, at $70^{\circ} \mathrm{C}$ for $2 \mathrm{~min}$. Proteins eluted from the beads were run on a $13.5 \%$ SDS-polyacrylamide gel and subjected to Western blotting.

\section{Acknowledgments}

We thank Joyce Li for generously providing us with purified wild-type RNA polymerase, groN785 RNA polymerase, ron RNA polymerase, NusA, NusAl, NusA785, NusB, NusG, and $\mathrm{N}$. We thank Dr. Volker Nowotny for generously providing us with purified S10 protein. We also thank Dr. Barbara Funnell for critically reviewing this manuscript. This work was supported by the Medical Research Council of Canada. J.G. is an International Research Scholar of the Howard Hughes Medical Institute.

The publication costs of this article were defrayed in part by payment of page charges. This article must therefore be hereby marked "advertisement" in accordance with 18 USC section 1734 solely to indicate this fact.

\section{References}

Aboussekhra, A., M. Biggerstaff, M.K.K. Shivji, J.A. Vilpo, V. Moncollin, V.N. Podust, M. Protic, U. Hubscher, J.M. Egly, and R.D. Wood. 1995. Mammalian DNA nucleotide excision repair reconstituted with purified protein components. Cell 80: $859-868$.

Albrechtsen, B., C.L. Squires, S. Li, and C. Squires. 1990. Antitermination of characterized transcriptional terminators by the Escherichia coli $r m G$ leader region. I. Mol. Biol. 213: $123-134$.

Altmann, C.R., D.E. Solow-Cordero, and M.J. Chamberlin. 1994. RNA cleavage and chain elongation by Escherichia coli DNA-dependent RNA polymerase in a binary enzymeRNA complex. Proc. Nat1. Acad. Sci. 91: 3784-3788.

Ausubel, F., R. Brent, R.E. Kingston, D.D. Moore, J.G. Seidman, J.A. Smith, and K. Struhl. 1987. Current protocols in molecular biology. John Wiley, New York.

Barik, S., B. Ghosh, W. Whalen, D. Lazinski, and A. Das. 1987. An antitermination protein engages the elongating transcription apparatus at a promoter-proximal recognition site. Cell 50: 885-899.

Berg, K.L., C. Squires, and C.L. Squires. 1989. Ribosomal RNA operon antitermination. Function of leader and spacer region boxB-box $A$ sequences and their conservation in diverse micro-organisms. J. Mol. Biol. 209: 345-358.

Burgess, R.R. and J.J. Jendrisak. 1975. A procedure for the rapid, large-scale purification of Escherichia coli DNA-dependent RNA polymerase involving polymin $\mathrm{P}$ precipitation and DNA-cellulose chromatography. Biochemistry 14: 4634-4638.

Chattopadhyay, S., J. Garcia-Mena, J. DeVito, K. Wolska, and A. Das. 1995. Bipartite function of a small RNA hairpin in transcription antitermination in bacteriophage $\lambda$. Proc. Natl. Acad. Sci. 92: 4061-4065.

Craven, M.G., A.E. Granston, A.T. Schauer, C. Zheng, T.A. Gray, and D.I. Friedman. 1994. Escherichia coli-Salmonella typhimurium hybrid nusA genes: Identification of a short motif required for action of the $\lambda \mathrm{N}$ transcription antitermination protein. J. Bacteriol. 176: 1394-1404.

Das, A. 1992. How the phage lambda $N$ gene product suppresses transcription termination: Communication of RNA polymerase with regulatory proteins mediated by signals in nascent RNA. I. Bacteriol. 174: 6711-6716.

Das, A., B. Ghosh, S. Barik, and K. Wolska. 1985. Evidence that ribosomal protein $\mathrm{S} 10$ itself is a cellular component necessary for transcription antitermination by phage $\lambda \mathrm{N}$ protein. Proc. Natl. Acad. Sci. 82: 4070-4074.

de Crombrugghe, B., M. Mudryi, R. DiLauro, and M. Gottesman. 1979. Specificity of the bacteriophage lambda $N$ gene product $(\mathrm{pN})$ : nut sequences are necessary and sufficient for antitermination by pN. Cell 18: 1145-1151.

Doelling, J.H. and N.C. Franklin. 1989. Effects of all single base substitutions in the loop of $b o x B$ on antitermination of transcription by bacteriophage $\lambda$ 's $N$ protein. Nucleic Acids Res. 17: 5565-5577. 
Downing, W.L., S.L. Sullivan, M.E. Gottesman, and P.P. Dennis. 1990. Sequence and transcriptional pattern of the essential Escherichia coli secE-nusG operon. J. Bacteriol. 172: 1621-1627.

Friedman, D.I. and L.S. Baron. 1974. Genetic characterization of a bacterial locus involved in the activity of the $\mathrm{N}$ function of phage lambda. Virology 58: 141-148.

Friedman, D.I. and E.R. Olson. 1983. Evidence that a nucleotide sequence, "box $A$ ", is involved in the action of the NusA protein. Cell 34: 143-149.

Friedman, D.I., M. Baumann, and L.S. Baron. 1976. Cooperative effects of bacterial mutations affecting lambda $N$ gene expression. I. Isolation and characterization of a nus $B$ mutant. Virology 73: 119-127.

Friedman, D.I., E.R. Olson, L. L. Johnson, D. Alessi, and M.G. Craven. 1990. Transcription-dependent competition for a host factor: The function and optimal sequence of the phage $\lambda$ box $A$ transcription antitermination signal. Genes \& Dev. 4: 2210-2222.

Georgopoulos, C.P. 1971. Bacterial mutants in which the gene $N$ function of bacteriophage lambda is blocked have an al tered RNA polymerase. Proc. Natl. Acad. Sci. 68: 2977-2981.

Ghysen, A. and M. Pironio. 1972. Relationship between the N function of bacteriophage lambda and host RNA polymerase. J. Mol. Biol. 65: 259-272.

Greenblatt, J. 1984. Regulation of transcription in Escherichia coli. Can. J. Biochem. Cell Biol. 62: 79-88.

Greenblatt, J. and J. Li. 1981a. The nusA gene protein of Escherichia coli: Its identification and a demonstration that it interacts with the gene $N$ transcription antitermination protein of bacteriophage lambda. I. Mol. Biol. 147: 11-23.

- $1981 \mathrm{~b}$. Interaction of the sigma factor and the nus $A$ gene protein of $E$. coli with RNA polymerase in the initiationtermination cycle of transcription. Cell 24: 421-428.

Greenblatt, J., P. Malnoe, and J. Li. 1980. Purification of the gene $N$ transcription antitermination protein of bacteriophage $\lambda$. J. Biol. Chem. 255: 1465-1470.

Greenblatt, J., J.R. Nodwell, and S.W. Mason. 1993. Transcriptional antitermination. Nature 364: 401-406.

Horowitz, D.S. and A.R. Krainer. 1994. Mechanisms for selecting 5 ' splice sites in mammalian pre-mRNA splicing. Trends Genet. 10: 100-108.

Horwitz, R.J., J. Li, and J. Greenblatt. 1987. An elongation control particle containing the $N$ gene transcriptional antitermination protein of bacteriophage lambda. Cell 51: 631-641.

Hsiao, K. 1991. A fast and simple procedure for sequencing double stranded DNA with sequenase. Nucleic Acids Res. 19: 2787.

Keppel, F., C. Georgopoulos, and H. Eisen. 1974. Host interference with expression of the lambda $N$ gene product. Biochimie 56: 1503-1509.

Lazinski, D., E. Grzadzielska, and A. Das. 1989. Sequence-specific recognition of RNA hairpins by bacteriophage antiterminators requires a conserved arginine-rich motif. Cell 59: 207-218.

Li, S.C., C.L. Squires, and C. Squires. 1984. Antitermination of E. coli rRNA transcription is caused by a control region seg ment containing lambda nut-like sequences. Cell 38: 851-860.

Li, J., R. Horwitz, S. McCracken, and J. Greenblatt. 1992. NusG, a new Escherichia coli elongation factor involved in transcriptional antitermination by the $\mathrm{N}$ protein of phage $\lambda$. $I$. Biol. Chem. 267: 6012-6019.

Li, J., S.W. Mason, and J. Greenblatt. 1993. Elongation factor NusG interacts with termination factor $\rho$ to regulate termination and antitermination. Genes \& Dev. 7: 161-172.

Mason, S.W. and J. Greenblatt. 1991. Assembly of transcription elongation complexes containing the $\mathrm{N}$ protein of phage $\lambda$ and the Escherichia coli elongation factors NusA, NusB, NusG, and S10. Genes \& Dev. 5: 1504-1512.

Mason, S.W., J. Li, and J. Greenblatt. 1992a. Host factor requirements for processive antitermination of transcription and suppression of pausing by the $\mathrm{N}$ protein of bacteriophage $\lambda$. J. Biol. Chem. 267: 19418-19426.

. 1992b. Direct interaction between two Escherichia coli transcription antitermination factors, NusB and ribosomal protein S10. J. Mol. Biol. 223: 55-66.

Morgan, E.A. 1986. Antitermination mechanisms in rRNA operons of Escherichia coli. J. Bacteriol. 168: 1-5.

Nodwell, J.R. 1993. "The recognition of antiterminator RNA by transcription factors in E. Coli." Ph.D. thesis. University of Toronto, Canada.

Nodwell, J.R. and J. Greenblatt. 1991. The nut site of bacteriophage $\lambda$ is made of RNA and is bound by transcription antitermination factors on the surface of RNA polymerase. Genes \& Dev. 5: 2141-2151.

1993. Recognition of boxA antiterminator RNA by the E. coli antitermination factors NusB and ribosomal protein S10. Cell 72: 261-268.

Olson, E.R., E.L. Flamm, and D.I. Friedman. 1982. Analysis of nut $R$ : A region of phage lambda required for antitermination of transcription. Cell 31: 61-70.

Olson, E.R., C.-S. Tomich, and D.I. Friedman. 1984. The nusA recognition site. Alteration in its sequence or position relative to upstream translation interferes with the action of the $\mathrm{N}$ antitermination function of phage lambda. $J$. Mol. Biol. 180: 1053-1063.

Patterson, T.A., Z. Zhang, T. Baker, L.L. Johnson, D.I. Friedman, and D.L. Court. 1994. Bacteriophage lambda N-dependent transcription antitermination: Competition for an RNA site may regulate antitermination. J. Mol. Biol. 236: 217-228.

Peltz, S.W., A.L. Brown, N. Hasan, A.J. Podhajska, and W. Szybalski. 1985. Thermosensitivity of a DNA recognition site: Activity of a truncated nutL antiterminator of coliphage lambda. Science 228: 91-93.

Robledo, R., M.E. Gottesman, and R.A. Weisberg. 1990. $\lambda$ nutR mutations convert HK022 Nun protein from a transcription termination factor to a suppressor of termination. $/ . \mathrm{Mol}$. Biol. 212: 635-643.

Rosenberg, M., D. Court, H. Shimatake, C. Brady, and D.L. Wulff. 1978. The relationship between function and DNA sequence in an intercistronic regulatory region of phage $\lambda$. Nature 272: 414-423.

Salstrom, J.S. and W. Szybalski. 1978. Coliphage $\lambda$ nut $L^{-}$: A unique class of mutants defective in the site of gene $\mathrm{N}$ product utilization for antitermination of leftward transcription. J. Mol. Biol. 124: 195-221.

Schauer, A.T., D.L. Carver, B. Bigelow, L.S. Baron, and D.I. Friedman. 1987. $\lambda \mathrm{N}$ antitermination system: Functional analysis of phage interactions with the host NusA protein. $J$. Mol. Biol. 194: 679-690.

Sparkowski, J. and A. Das. 1992. Simultaneous gain and loss of functions caused by a single amino acid substitution in the $\beta$ subunit of Escherichia coli RNA polymerase: Supression of nusA and rho mutations and conditional lethality. Genetics 130: 411-428.

Steege, D.A., K.C. Cone, C. Queen, and M. Rosenberg. 1987. Bacteriophage $\lambda N$ gene leader RNA. RNA processing and translational initiation signals. J. Biol. Chem. 262: 1765117658.

Stillman, B. 1994. Smart machines at the DNA replication fork. Cell 78: 725-728.

Sullivan, S.L., D.F. Ward, and M.E. Gottesman. 1992. Effect of Escherichia coli nus $G$ function on $\lambda \mathrm{N}$-mediated transcrip- 
tion antitermination. J. Bacteriol. 174: 1339-1344.

Swindle, J., C. Zylicz, C. Georgopoulos, J. Li, and J. Greenblatt. 1988. Purification and properties of the NusB protein of Escherichia coli. J. Biol. Chem. 263: 10229-10235.

Tan, R. and A.D. Frankel. 1995. Structural variety of argininerich RNA-binding peptides. Proc. Natl. Acad. Sci. 92: 52825286.

Ward, D.F., A. DeLong, and M.E. Gottesman. 1983. Escherichia coli nus $B$ mutations that suppress nus $A 1$ exhibit $\lambda \mathrm{N}$ specificity. J. Mol. Biol. 168: 73-85.

Whalen, W.A. and A. Das. 1990. Action of an RNA site at a distance: Role of the nut genetic signal in transcription antitermination by phage- $\lambda$ N gene product. New Biol. 2: 975-991.

Whalen, W., B. Ghosh, and A. Das. 1988. NusA protein is necessary and sufficient in vitro for phage $\lambda \mathrm{N}$ gene product to suppress a $\rho$-independent terminator placed downstream of nutL. Proc. Natl. Acad. Sci. 85: 2494-2498.

Zawel, L. and D. Reinberg. 1993. Initiation of transcription by RNA polymerase II: A multi-step process. In Progress in nucleic acid research and molecular biology fed. W. E. Cohn and K. Moldave), pp. 67-108. Academic Press, San Diego, CA.

Zuber, M., T.A. Patterson, and D.L. Court. 1987. Analysis of nut $R$, a site required for transcription antitermination in phage A. Proc. Natl. Acad. Sci. 84: 4514-4518. 


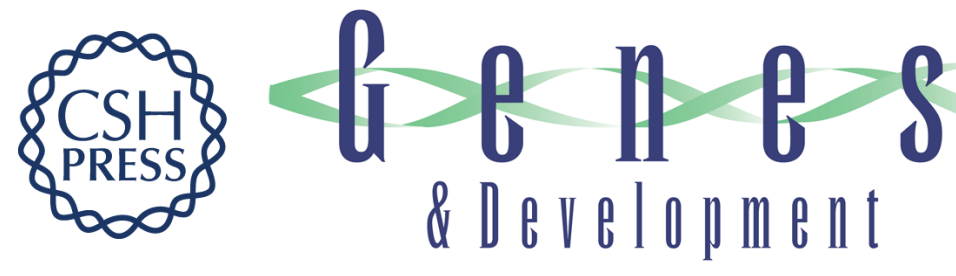

\section{A protein-RNA interaction network facilitates the template-independent cooperative assembly on RNA polymerase of a stable antitermination complex containing the lambda $\mathrm{N}$ protein.}

J Mogridge, T F Mah and J Greenblatt

Genes Dev. 1995, 9:

Access the most recent version at doi:10.1101/gad.9.22.2831

References This article cites 56 articles, 23 of which can be accessed free at:

http://genesdev.cshlp.org/content/9/22/2831.full.html\#ref-list-1

License

Email Alerting Receive free email alerts when new articles cite this article - sign up in the box at the top Service right corner of the article or click here.

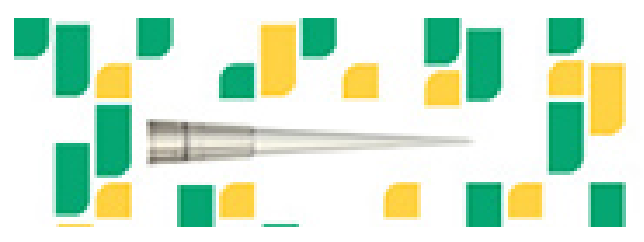

Focused on your science. 